\title{
Executive Functions
}

\author{
Adele Diamond \\ Department of Psychiatry, University of British Columbia and BC Children's Hospital, Vancouver, \\ BC V6T 2A1 Canada; adele.diamond@ubc.ca
}

\section{Abstract}

Executive functions (EFs) make possible mentally playing with ideas; taking the time to think before acting; meeting novel, unanticipated challenges; resisting temptations; and staying focused. Core EFs are inhibition [response inhibition (self-control—resisting temptations and resisting acting impulsively) and interference control (selective attention and cognitive inhibition)], working memory, and cognitive flexibility (including creatively thinking "outside the box," seeing anything from different perspectives, and quickly and flexibly adapting to changed circumstances). The developmental progression and representative measures of each are discussed. Controversies are addressed (e.g., the relation between EFs and fluid intelligence, self-regulation, executive attention, and effortful control, and the relation between working memory and inhibition and attention). The importance of social, emotional, and physical health for cognitive health is discussed because stress, lack of sleep, loneliness, or lack of exercise each impair EFs. That EFs are trainable and can be improved with practice is addressed, including diverse methods tried thus far.

\section{Keywords}

cognitive control; self-regulation; creativity; attention; reasoning; working memory; fluid intelligence; inhibitory control; task switching; mental flexibility

\section{INTRODUCTION}

Executive functions (EFs; also called executive control or cognitive control) refer to a family of top-down mental processes needed when you have to concentrate and pay attention, when going on automatic or relying on instinct or intuition would be ill-advised, insufficient, or impossible (Burgess \& Simons 2005, Espy 2004, Miller \& Cohen 2001). Using EFs is effortful; it is easier to continue doing what you have been doing than to change, it is easier to give into temptation than to resist it, and it is easier to go on "automatic pilot" than to consider what to do next. There is general agreement that there are three core EFs (e.g., Lehto et al. 2003, Miyake et al. 2000): inhibition [inhibitory control, including self-control (behavioral inhibition) and interference control (selective attention and cognitive inhibition)], working memory (WM), and cognitive flexibility (also called set

Copyright $\odot 2013$ by Annual Reviews. All rights reserved

DISCLOSURE STATEMENT The author is not aware of any affiliations, memberships, funding, or financial holdings that might be perceived as affecting the objectivity of this review. 
shifting, mental flexibility, or mental set shifting and closely linked to creativity). From these, higher-order EFs are built such as reasoning, problem solving, and planning (Collins \& Koechlin 2012, Lunt et al. 2012). EFs are skills essential for mental and physical health; success in school and in life; and cognitive, social, and psychological development (see Table 1).

\section{INHIBITORY CONTROL}

Inhibitory control (one of the core EFs) involves being able to control one's attention, behavior, thoughts, and/or emotions to override a strong internal predisposition or external lure, and instead do what's more appropriate or needed. Without inhibitory control we would be at the mercy of impulses, old habits of thought or action (conditioned responses), and/or stimuli in the environment that pull us this way or that. Thus, inhibitory control makes it possible for us to change and for us to choose how we react and how we behave rather than being unthinking creatures of habit. It doesn't make it easy. Indeed, we usually are creatures of habit and our behavior is under the control of environmental stimuli far more than we usually realize, but having the ability to exercise inhibitory control creates the possibility of change and choice. It can also save us from making fools of ourselves.

Inhibitory control of attention (interference control at the level of perception) enables us to selectively attend, focusing on what we choose and suppressing attention to other stimuli. We need such selective attention at a cocktail party when we want to screen out all but one voice. A salient stimulus such as visual motion or a loud noise attracts our attention whether we want it to or not. That is called exogenous, bottom-up, automatic, stimulus-driven, or involuntary attention and is driven by properties of stimuli themselves (Posner \& DiGirolamo 1998, Theeuwes 1991). We can also choose voluntarily to ignore (or inhibit attention to) particular stimuli and attend to others based on our goal or intention. Besides being called selective or focused attention, this has been termed attentional control or attentional inhibition, endogenous, top-down, active, goal-driven, voluntary, volitional, or executive attention (Posner \& DiGirolamo 1998, Theeuwes 2010).

Another aspect of interference control is suppressing prepotent mental representations (cognitive inhibition). This involves resisting extraneous or unwanted thoughts or memories, including intentional forgetting (Anderson \& Levy 2009), resisting proactive interference from information acquired earlier (Postle et al. 2004), and resisting retroactive interference from items presented later. Cognitive inhibition is usually in the service of aiding WM and is discussed in the section Inhibitory Control Supports Working Memory. It tends to cohere more with WM measures than with measures of other types of inhibition.

Self-control is the aspect of inhibitory control that involves control over one's behavior and control over one's emotions in the service of controlling one's behavior. Self-control is about resisting temptations and not acting impulsively. The temptation resisted might be to indulge in pleasures when one should not (e.g., to indulge in a romantic fling if you are married or to eat sweets if you are trying to lose weight), to overindulge, or to stray from the straight and narrow (e.g., to cheat or steal). Or the temptation might be to impulsively react (e.g., reflexively striking back at someone who has hurt your feelings) or to do or take what 
you want without regard for social norms (e.g., butting in line or grabbing another child's toy).

Another aspect of self-control is having the discipline to stay on task despite distractions and completing a task despite temptations to give up, to move on to more interesting work, or to have a good time instead. This involves making yourself do something or keep at something though you would rather be doing something else. It is related to the final aspect of selfcontrol-delaying gratification (Mischel et al. 1989)—making yourself forgo an immediate pleasure for a greater reward later (often termed delay discounting by neuroscientists and learning theorists; Louie \& Glimcher 2010, Rachlin et al. 1991). Without the discipline to complete what one started and delay gratification, no one would ever complete a long, timeconsuming task such as writing a dissertation, running a marathon, or starting a new business.

Although the above examples typically involve a tug-of-war between a part of you that wants to do $x$ and another part of you that wants to do $y$ (Hofmann et al. 2009), self-control can be needed where there are not competing desires. It is needed, for example, to not blurt out what first comes to mind (which might be hurtful to others or embarrassing to you), to not jump to a conclusion before getting all the facts, or to not give the first answer that occurs to you when if you took more time you could give a better, wiser response.

Errors of impulsivity are errors of not being able to wait. If someone can be helped to wait such errors can often be avoided. Many of us have had the experience of pressing the "send" button for an email only to wish we had not. Many of us have also had the experience of our first interpretation of the intention behind someone's words or actions being incorrect, and we have either been grateful we exercised the self-control to wait until we acquired more information or regretted that we acted precipitously without waiting. On laboratory tasks, young children often rush to respond and thus make errors by giving the prepotent response when a different response is required. Helping young children wait improves their performance. This has been shown using a variety of inhibitory control tasks such as go/nogo (Jones et al. 2003), theory of mind (Heberle et al. 1999), day-night (Diamond et al. 2002), and a Piagetian search task (Riviere \& Lecuyer 2003). The subthalamic nucleus appears to play a critical role in preventing such impulsive or premature responding (Frank 2006).

Diamond and colleagues (2002) hypothesized that more time helps in such situations because young children need time to compute the answer. Simpson \& Riggs (2007) hypothesized that more time helps because it allows the prepotent response (which is triggered automatically by a stimulus) to race to the response threshold and then fade, enabling the correct answer to compete more successfully [to do something other than your prepotent response requires mental effort and reaches the response threshold more slowly (Figure 1; see Band et al. 2003)]. Diamond, Simpson, and Riggs (Simpson et al. 2012) teamed up to test between their hypotheses. The results clearly support Simpson and Riggs's passive-dissipation hypothesis. In a distraction-during-delay condition, preschoolers were able to resist opening boxes on no-go trials. They performed well on such trials despite not 
being able to compute anything during the delay because they were occupied with a guessing game.

When an incorrect prepotent response is elicited by the sight of a stimulus, individuals can be helped to perform correctly by shielding the stimulus from view, thus reducing or eliminating the need for inhibitory control. For example, in Piaget's famous test of conservation of liquid volume (Piaget 1952/1941), the same amount of liquid is poured into a short, fat beaker and a tall, thin beaker. Of course the water level is much higher in the tall, thin beaker, creating a perceptual pull to think there is more water there. Children of 4 to 5 years, who have just certified that the amount of liquid is the same in two identical short beakers, fall prey to this perceptual pull. Though they see the liquid poured from one of the short beakers into the taller, thinner beaker, upon seeing the higher level of liquid in the tall beaker, they assert there must be more liquid there. However, if they are shielded from seeing the two different levels of liquid and are simply asked which beaker has more liquid, children of 4 to 5 years give the correct answer (Bruner et al. 1966).

Similarly, infants have a prepotent tendency to reach directly for a visible reward. If a transparent barrier is between them and the reward, infants of 6 to 11 months have great difficulty inhibiting the perceptual pull to keep trying to reach straight for the reward despite repeatedly being thwarted by the clear barrier. If the barrier is opaque, thus removing the perceptual pull, more infants at each age succeed in detouring around the barrier and succeed in less time (Diamond 1990, 1991). Many adults use a related strategy by eliminating fattening foods from view when they are trying to diet, thus reducing the degree of self-control needed.

\section{Representative Psychological Tasks Used to Assess Inhibitory Control}

Examples of other psychological measures of inhibitory control include the Stroop task (MacLeod 1991), Simon task (Hommel 2011), Flanker task (Eriksen \& Eriksen 1974, Mullane et al. 2009), antisaccade tasks (Luna 2009, Munoz \& Everling 2004), delay-ofgratification tasks (Kochanska et al. 2001, Sethi et al. 2000), go/no-go tasks (Cragg \& Nation 2008), and stop-signal tasks (Verbruggen \& Logan 2008). One of the many hotly debated aspects of EFs is which component(s) of EFs a task requires. Not everyone agrees that these tasks require inhibitory control [see, for example, MacLeod et al. (2003) on the Stroop task and Roberts \& Pennington (1996) on the antisaccade task].

We are trained to read for meaning and to largely ignore superficial characteristics of words such as font style or color of the ink. Incongruent trials on the Stroop task present color words (such as "green") written in the color of another ink ("red"). When required to ignore the meaning of the word (i.e., inhibit our prepotent response to words) and instead attend to and report the color of the ink, people are slower and make more errors.

Simon tasks present two very simple rules: for Stimulus A press on the left; for Stimulus B press on the right. Only one stimulus appears at a time; either stimulus can appear on the right or the left. Although location of the stimulus is irrelevant, people respond more slowly when the stimulus appears on the side opposite its associated response (termed the Simon effect, spatial incompatibility, or stimulus-response compatibility), indicating that we have a 
prepotent tendency to respond on the same side as a stimulus (Hommel 2011, Lu \& Proctor 1995). That tendency must be inhibited when the locations of stimulus and response are opposite (incompatible). Indeed, when monkeys are to point away from a stimulus, the neuronal population vector in primary motor cortex (coding the direction of planned movement) initially points toward the stimulus and only then shifts to the required direction (showing a prepotent tendency at the neuronal level to respond toward a stimulus; to do otherwise requires that that impulse be inhibited; Georgopoulos et al. 1989). For comparable results in humans see Valle-Inclán (1996).

The Spatial Stroop task is similar to a Simon task but minimizes memory demands because the stimulus shows you where to respond. You are to press in the direction the arrow is pointing. Sometimes the arrow appears on the side it is pointing toward (congruent, compatible trials), but sometimes the arrow appears on the other side (incongruent, incompatible trials). The arrow's location is irrelevant, but subjects still have a tendency to press on the side the arrow appears, which must be inhibited when the arrow is pointing in the opposite direction. A version of the Spatial Stroop task appears in the Cambridge Neuropsychological Test Automated Battery (CANTAB; Sahakian et al. 1988).

The Flanker task requires selective attention; you are to attend to the centrally presented stimulus and ignore the flanking stimuli surrounding it. When the flanking stimuli are mapped to the opposite response from the center stimulus (incompatible trials), subjects respond more slowly because of the need to exercise top-down control (Eriksen \& Eriksen 1974).

Our natural tendency is to look toward a salient stimulus when it appears (i.e., to make a prosaccade). On trials where we are instructed to inhibit that tendency and instead do the opposite (i.e., to look away from the stimulus, to make an antisaccade), we are slower and more prone to err (Munoz \& Everling 2004). This task is sensitive to developmental improvements throughout late childhood and adolescence (Luna 2009, Luna et al. 2004).

Delay-of-gratification tasks involve placing a delicious snack before young children and asking that they wait before taking it. Children can have more of the treat if they wait, or less if they can't wait. Each child is tested individually. Retesting is difficult because it is critical that the child not know how long the wait will be. This task seems to predict children's EFs and academic performance at much later ages (Eigsti et al. 2006).

Two widely used measures of response inhibition - the go/no-go and stop-signal tasks-are different from other measures in that participants do not inhibit one response to make another; they simply inhibit a response to do nothing. Go/no-go tasks require that you usually press a button when a stimulus appears, but when a certain stimulus appears you should not press. On the stop-signal task, the go signal is presented on all trials; on a minority of trials after the go signal and just as the subject is about to respond, a stop signal appears (usually a sound), indicating that one should not press the button on that trial. Realworld analogies of checking an action that was just on the verge of being made would be when a situation, or your evaluation of it, suddenly changes such as when you are about to cross the street and the light suddenly changes or a batter checks a swing. The go/no-go and 
stop-signal tasks are not identical in their inhibitory requirements (Verbruggen \& Logan 2008) and differ from many real-world instances of inhibitory control (Aron 2011). Rather than being paradigmatic examples of when inhibitory control is needed, they appear to be unusual cases.

\section{Commonalities and Differences Among Diverse Forms of Inhibitory Control}

Are the different aspects of inhibitory control dissociable from one another? Is the same neural system required to resist internal and external distractions? Is the neural system that subserves cognitive inhibition the same as that subserving inhibition of attention and/or action? Is the neural system that subserves inhibition in attention (interference control/ selective attention) the same neural system that subserves inhibition in action (inhibiting a prepotent response tendency)? Certainly the forms of inhibition seem quite disparate (Nigg 2000). Yet evidence indicates that diverse types of inhibitory control of attention and action appear to share substantially similar neural bases (Bunge et al. 2002, Cohen et al. 2012). Cognitive inhibition, however, appears to be dissociable (Engelhardt et al. 2008, Friedman $\&$ Miyake 2004). There is some emerging evidence that delay of gratification might be dissociable as well (Diamond \& Lee 2011).

Factor analyses have found that inhibition of attention (resisting distractor interference) and inhibition of action (inhibiting a prepotent response) are strongly correlated and fall along a single factor (Friedman \& Miyake 2004). It is consistently found that when required to exert one type of self-control (e.g., resisting sweets), and then immediately after a second type of self-control in a superficially completely unrelated domain (e.g., the stop-signal task), people are more impaired on the second task than if they did a different difficult task first that did not require self-control (e.g., math calculations; Muraven 2010, Muraven \& Baumeister 2000).

Is the neural system required to inhibit an action and not act at all (e.g., on no-go trials) the same as the system required to inhibit one action to do another? Petrides (1986) and de Jong et al. (1995) suggest it is not. Is the neural system that underlies the ability to inhibit an unwanted action the same as the system underlying the ability to check a desired action (e.g., as in not swinging at a poorly pitched ball or as on the stop-signal task)? Do all of these forms of inhibition develop concurrently, and are they equally susceptible to disruption because of a particular genetic abnormality or environmental insult during development? If they are separable, how are we to divide them into components (Casey 2001, Nigg 2000)? Certainly automatic inhibition (such as that seen in the attentional blink or negative priming) is dissociable from the volitional, effortful inhibitory control discussed here (Carr et al. 2006, Nigg et al. 2002), and although effortful inhibition declines with aging, it is unclear whether automatic inhibition does (Gamboz et al. 2002).

\section{Development of Inhibitory Control}

Inhibitory control is disproportionately difficult for young children. For example, the difference in both the speed and accuracy of children's performance at all ages from 4 to 9 between $(a)$ always responding on the same side as a stimulus and $(b)$ inhibiting that prepotent tendency and always responding on the side opposite a stimulus is greater than the 
difference in their speed or accuracy for $(a)$ holding two stimulus-response associations in mind versus (b) holding six stimulus-response associations in mind (Davidson et al. 2006; see Figure 2). That's true whether the same-side trials come before or after the opposite-side ones (Wright \& Diamond 2012). The reverse is true for adults. It is far harder for us to hold six associations in mind than only two, but it is no harder for us to always respond on the side opposite a stimulus than to always respond on the same side as a stimulus (our speed and accuracy for each are equivalent; Davidson et al. 2006, Lu \& Proctor 1995). Inhibitory control continues to mature during adolescence (Luna 2009, Luna et al. 2004).

Inhibitory control early in life appears to be quite predictive of outcomes throughout life, including in adulthood. When 1,000 children born in the same city in the same year were followed for 32 years with a $96 \%$ retention rate, Moffitt et al. (2011) found that children who at ages 3 to 11 had better inhibitory control (e.g., were better at waiting their turn, less easily distracted, more persistent, and less impulsive) were more likely as teenagers to still be in school and were less likely to make risky choices or to be smoking or taking drugs. They grew up to have better physical and mental health (e.g., were less likely to be overweight or to have high blood pressure or substance abuse problems), earn more, and be more law-abiding as adults 30 years later than were those with worse inhibitory control as children, controlling for IQ, gender, social class, and their home lives and family circumstances growing up. They were also happier as adults (Moffitt 2012).

Inhibitory control declines noticeably during normal aging, however (Hasher \& Zacks 1988, Hasher et al. 1991). For example, older adults are poor at inhibiting visual distractions (Darowski et al. 2008, Gazzaley et al. 2005) and auditory distractions (Alain \& Woods 1999, Barr \& Giambra 1990). Older adults show normal enhancement of the to-be-attended stimuli, but less or even no suppression of the stimuli to be ignored (Gazzaley et al. 2005), providing rather strong evidence of an inhibitory-control deficit in aging. No matter whether participants are prepared for distraction or not, and regardless of how long the period between the forewarning and stimuli or how long the interval between trials, older adults are substantially worse than younger adults in suppressing irrelevant information (Zanto et al. 2010). Older adults' inhibitory-control problems are also evident on the antisaccade task (Peltsch et al. 2011, Sweeney et al. 2001).

\section{WORKING MEMORY}

Another core EF is working memory (WM), which involves holding information in mind and mentally working with it (or said differently, working with information no longer perceptually present; Baddeley \& Hitch 1994, Smith \& Jonides 1999). The two types of WM are distinguished by content-verbal WM and nonverbal (visual-spatial) WM. WM is critical for making sense of anything that unfolds over time, for that always requires holding in mind what happened earlier and relating that to what comes later. Thus it is necessary for making sense of written or spoken language whether it is a sentence, a paragraph, or longer. Doing any math in your head requires WM, as does mentally reordering items (such as reorganizing a to-do list), translating instructions into action plans, incorporating new information into your thinking or action plans (updating), considering alternatives, and mentally relating information to derive a general principle or to see relations between items 
or ideas. Reasoning would not be possible without WM. WM is critical to our ability to see connections between seemingly unrelated things and to pull apart elements from an integrated whole, and hence to creativity because creativity involves disassembling and recombining elements in new ways. WM also enables us to bring conceptual knowledge and not just perceptual input to bear on our decisions, and to consider our remembered past and future hopes in making plans and decisions.

\section{Working Memory Versus Short-Term Memory}

WM (holding information in mind and manipulating it) is distinct from short-term memory (just holding information in mind). They cluster onto separate factors in factor analyses of children, adolescents, and adults (Alloway et al. 2004, Gathercole et al. 2004). They are linked to different neural subsystems. WM relies more on dorsolateral prefrontal cortex, whereas maintaining information in mind but not manipulating it [as long as the number of items is not huge (suprathreshold)] does not need involvement of dorsolateral prefrontal cortex (D'Esposito et al. 1999, Eldreth et al. 2006, Smith \& Jonides 1999). Imaging studies show frontal activation only in ventrolateral prefrontal cortex for memory maintenance that is not suprathreshold.

WM and short-term memory also show different developmental progressions; the latter develops earlier and faster. A Simon task (described above) requires that subjects remember two rules (for Stimulus 1 press on the right; for Stimulus 2 press on the left). A super-ficially similar task, originally called the Dots task and later renamed the Hearts and Flowers task, also requires that subjects remember two rules (for Stimulus 1 press on the same side as the stimulus; for Stimulus 2 press on the side opposite the stimulus; Davidson et al. 2006, Diamond et al. 2007). Whereas the memory component of the Simon task requires only holding information in mind, note that WM is required for the Dots task because the instruction to use the hand on the same or opposite side as the stimulus must be translated into whether to use the right or left hand. The rules must not only be held in mind but also mentally translated or transformed. Comparing performance on the Simon and Dots tasks across age provides a clear view of the additional toll that WM versus short-term memory exacts for children at least through ages 4 to 13 and for adults (see Figure 3; Davidson et al. 2006).

\section{Relations Between Working Memory and Inhibitory Control}

They generally need one another and co-occur-One prototypical instance of when EFs are needed is the class of situations where you are to act counter to your initial tendency on the basis of information held in mind. WM and inhibitory control support one another and rarely, if ever, is one needed but not the other.

Working memory supports inhibitory control-You must hold your goal in mind to know what is relevant or appropriate and what to inhibit. By concentrating especially hard on the information you are holding in mind, you increase the likelihood that that information will guide your behavior, and you decrease the likelihood of an inhibitory error (mistakenly emitting the default, or normally prepotent, response when it should have been inhibited). 
Using visual cues to help young children remember what they were just told can markedly improve their inhibitory control performance. For example, a school program for 4- to 5year-olds called Tools of the Mind uses visual aids in an activity called Buddy Reading (Bodrova \& Leong 2007). Each child chooses a picture book, pairs up with another child, and they are to take turns telling the story that goes with their book. With each child eager to tell his or her story, no one wants to listen. To help children succeed at inhibitory control, teachers use a visual memory aid, handing one child in each pair a drawing of an ear, explaining, "Ears don't talk; ears listen." With that concrete reminder, the child with the ear inhibits talking and listens. Without it, the child would not be able to do that. After a few months, the picture is no longer needed; the child has internalized the reminder.

Inhibitory control supports working memory-To relate multiple ideas or facts together you must be able to resist focusing exclusively on just one thing, and to recombine ideas and facts in new, creative ways you need to be able to resist repeating old thought patterns. To keep your mind focused on what you want to focus on you must inhibit internal and external distractions. When such inhibition fails, your mind may wander. Many of us are familiar with suddenly realizing that we don't know what was in the passage we supposedly just read because our mind was elsewhere (it had wandered). Several studies have explored such mind-wandering (e.g., Kane et al. 2007, Mason et al. 2007, Smallwood \& Schooler 2009). Meditation is reported to reduce mind-wandering by disciplining the mind in the art of staying focused (Hölzel et al. 2011, Zeidan et al. 2010). Inhibitory control can also aid WM by helping to keep our mental workspace from becoming too cluttered by suppressing extraneous thoughts (i.e., gating out irrelevant information from the WM workspace), resisting proactive interference by deleting no-longer-relevant information from that limitedcapacity workspace (Hasher \& Zacks 1988, Zacks \& Hasher 2006). Hasher and Zacks group cognitive inhibition under WM. As noted above, they may be right that inhibition in the service of protecting the mental workspace for WM is intrinsically allied with WM.

An excellent example of not cluttering one's WM space unnecessarily can be seen with an interesting test developed by Duncan et al. (2008). One group of subjects is instructed on two tasks (a letter task and a number task) and then told they can ignore the number task for the time being because they will only be doing the letter task now. Another group is instructed only on the letter task. The stimuli are presented in two columns. Subjects are instructed that when they see a plus sign they should attend to the column on the right, while a minus sign means attend to the column on the left. When asked before or after testing, all subjects correctly recall what they should do for a plus or minus sign. Everyone obeys those rules perfectly when instructed on only one task. However, when instructed on two tasks, individuals with worse EFs often fail to switch columns when they should. Almost all participants who scored $>1$ standard deviation below the population mean on a reasoning measure of EFs neglected to observe the plus- and minus-sign rules. Almost no one scoring above the mean on the EF measure did so.

Why would persons with poorer EFs obey the plus- and minus-sign rules when instructed on only one task but ignore them when performing exactly the same task after initially being instructed on a second task they are told to ignore? Presumably it is because they failed to clear the irrelevant task from their mental workspace (they failed to inhibit or suppress it), 
and so it was cluttering up their limited-capacity WM. In neither condition do they fail to remember the plus- and minus-sign rules; it is simply that in the more-complete instruction condition they fail to act according to those rules.

If the source of their problem is, as we suspect, trying to hold more in WM than is necessary, it is reminiscent of problems young children have. By 10 to 12 months, infants can successfully retrieve an object they see hidden first at Place A and then at Place B even after a five-second delay between hiding and retrieval (A-not-B task; Diamond 1985). Not until a year and a half later do toddlers reliably retrieve an object when they see it placed inside a container and then see that container hidden at Place A and then at Place B with a five-second delay between hiding and retrieval (A-not-B with invisible displacement; Diamond et al. 1997). For adults the two tasks are comparable-remember whether the reward was hidden at $\mathrm{A}$ or $\mathrm{B}$ on this trial. It appears that infants try to hold too much in mind when faced with invisible displacement (i.e., that the toy is in the container, and the container was hidden at A or B).

Performance of adults with poorer EFs on the Duncan et al. task is also reminiscent of 3year-olds on the Dimensional Change Card Sort task (Zelazo et al. 1996). Children of 3 years can sort flawlessly by either color or shape, but when instructed to switch the dimension they are sorting by, they continue to sort by the first dimension. Yet, if you ask them, they can tell you that the second dimension is now relevant, what it is, and how to sort by it (Cepeda \& Munakata 2007, Zelazo et al. 1996). It is not that they have forgotten which dimension is relevant or how to sort by it (just as adults with poorer EFs have not forgotten the plus- and minus-sign rules). It is simply that members of neither group use that information to guide their behavior.

Disentangling working memory and inhibitory control-If WM and inhibitory control are so intertwined, is it never possible to ask research questions specific to one or the other? No, it is possible. The influence of either WM or inhibitory control can be minimized or controlled for. For example, on the Hearts and Flowers (previously known as the Dots) task, the congruent and incongruent blocks both involve holding one rule in mind. They differ only in the inhibitory demand present in the incongruent block. Counterbalancing order of presentation of the two blocks (to control for possible order or switching effects), poorer performance on the incongruent block provides an indication of the cost of having to inhibit the prepotent tendency to respond on the same side as the stimulus, controlling for memory demands. A Spatial Stroop task places minimal demands on memory because the stimuli themselves tell you where to respond (eyes looking left or right, or arrows pointing left or right), so performance costs in the incongruent condition of a Spatial Stroop task should primarily be due to difficulty inhibiting the prepotent tendency to respond on the same side as the stimulus.

Conversely, reordering items one has heard according to a rule (e.g., alphabetical or numerical order, size, or distance from a point) requires little attentional or response inhibition and so is a relatively pure measure of WM (plus cognitive inhibition). Comparing performance on the Hearts and Flowers task with a control version ("When the eyes look straight down, press on the same side as the stimulus"; "When the eyes look diagonally to 
the opposite side, press on the opposite side as the stimulus") enables one to determine the performance cost of having to use WM versus just looking at the stimulus to see where to respond.

Is successful inhibitory control but a result of good working memory?-There is disagreement among EF researchers over whether inhibition is separate from WM or whether inhibition is a behavioral product of exercising WM, not a separate cognitive skill. A third view is that WM and inhibition depend on the same limited-capacity system so that increasing the demand on either affects one's ability to do the other (e.g., Engle \& Kane 2004, Wais \& Gazzaley 2011). The view that WM is primary and inhibitory control derivative has a number of supporters (e.g., Egner \& Hirsch 2005, Hanania \& Smith 2010, Nieuwenhuis \& Yeung 2005). That view is held universally among those who do computational modeling (Miller \& Cohen 2001, Munakata et al. 2011). Activation alone is seen as sufficient; there is no need to posit suppression or inhibition. If you are holding your goal firmly enough in mind, you will act appropriately. Representation of one's goal can be more or less robust in WM; when it is weak or fuzzy, one's prepotent behavioral inclination might win out in competition with it (e.g., Munakata et al. 2011).

Other researchers find empirically that suppression (inhibitory control) and enhancement (activation of goals in WM) are indeed dissociable (e.g., Davidson et al. 2006, Gernsbacher \& Faust 1991, Zanto et al. 2011). For example, when one stimulus is superimposed on another, and subjects are instructed to attend to stimuli in the outer layer, ignoring the background stimuli, older adults show normal enhancement of the to-be-attended stimuli but little or no suppression of the to-be-ignored stimuli, leading Zanto et al. (2011) to conclude that enhancement and suppression rely on distinct mechanisms, that "suppression is not simply lack of enhancement" (p. 660). The debate continues.

One type of failure of EFs is action slips, where we intend to do one thing but do something else instead (the usual, habitual, or most easily elicited action). On such occasions it is as if we let ourselves run on automatic when we should have been paying attention (when we should have been exercising our EFs). Examples would be (a) dialing a friend's old phone number when you know your friend has a new number and probably even reminded yourself when you sat down to call or $(b)$ wanting to diverge from your normal route home to do an errand but find that you have driven past the turning point and are headed straight for home.

A large proportion of absent-minded errors actually take the form of intact, wellorganized segments of skilled action that are suitable for the environmental context most of the time, but not when changed circumstances require some alteration of normal practice (Reason \& Mycielska 1982, pp. 39-40).

Such slips appear to be due to not attending to the goal you are holding in mind. You know perfectly well what you meant to do. If asked, you can immediately state the goal. For a few moments or longer, however, your attention wondered, and without any top-down instructions to do otherwise, you simply did the usual.

The cause of such action errors seems fundamentally different from other instances when people appear to act counter to their intent. One example might be eating luscious chocolate 
cake when you want to lose weight. When I've done this, there was no temporary lapse in attending to the goal of losing weight; I had that clearly in mind. However, there were two competing goals, and chocolate-now won out over weight-loss-later. A different type of example might be impulsively reacting so quickly that your words or actions come out before top-down control can inhibit them and generate a more considered response (see Figure 1 above). These types of action errors do not seem to arise from a WM lapse or deficit.

\section{Theories of working memory that incorporate aspects of inhibitory control} under what is called working memory-Although EF researchers refer to WM as a subcomponent of EFs, many working-memory researchers use the term WM far more broadly so that it becomes roughly synonymous with EFs. For example, Engle and Kane define WM as the ability to (a) maintain selected information in an active, easily retrievable state while $(b)$ inhibiting (blocking) distractors and interference (i.e., short-term memory + interference control at the attentional and cognitive levels; Conway \& Engle 1994; Kane \& Engle 2000, 2002). Functions of the central executive in Baddeley's working-memory model (Baddeley \& Hitch 1994) include inhibitory control and cognitive flexibility: (a) multitasking, $(b)$ shifting between tasks or retrieval strategies, and $(c)$ the capacity to attend and inhibit in a selective manner. My own preference would be to reserve the term WM to mean only holding information in mind and working with it (working with information not perceptually present).

\section{Working Memory and Selective, Focused Attention}

Focusing on information held in mind for several seconds might as easily be called keeping your attention focused on those mental contents for several seconds. WM and selective, focused attention appear to be similar in many ways, including neural basis. The prefrontalparietal system that supports WM, enabling us to selectively remain focused on information held in mind, tuning out irrelevant thoughts, overlaps substantially with the prefrontal parietal system that helps us selectively attend to stimuli in our environment, tuning out irrelevant stimuli (e.g., Awh et al. 2000, Awh \& Jonides 2001, Gazzaley \& Nobre 2012, Ikkai \& Curtis 2011, LaBar et al. 1999, Nobre \& Stokes 2011). Simulations have demonstrated that developmental improvements in WM can support developmental improvements in selective attention (Stedron et al. 2005). People are quicker to notice, and respond to, stimuli in a location they are holding in WM, and if forced to orient their attention away from a location they are trying to hold in WM, their memory accuracy suffers (Awh \& Jonides 2001, Kuo et al. 2012, Wais et al. 2010).

\section{Representative Psychological Tasks Used to Assess Working Memory}

Forward-digit span tasks (repeat back items in the order in which you heard them) are a measure of short-term memory, not WM, as they only require holding information in mind. Backward-digit span (say the items back in reverse order) comes closer to being a WM task unless a person can see in his or her mind the items that were said and simply read them off from last to first. Asking subjects to reorder the items they have heard is an excellent WM measure. It might be repeating the numbers they have just heard (perhaps 6, 9, 4,7) in numerical order $(4,6,7,9)$, repeating items back reordered by size (e.g., reordering cat, 
elephant, ant, tiger into the order ant, cat, tiger, elephant), or reordered by distance from points A and B to make the most efficient route. Here, A might be work and B might be home, and the items might be grocers, cleaners, gas station, and post office.

A widely used measure of visual-spatial WM is the Corsi Block test (Lezak 1983). A subject watches the tester touch a series of blocks, then the subject is to touch the blocks in the same order. A computerized version of this and of backward digit span appears in the Automated Working Memory Assessment (AWMA) battery (Alloway 2007, Alloway et al. 2009). It has been standardized on 1,470 children ages 5 to 6 years and 1,719 children ages 8 to 9 years (Alloway et al. 2009), and it has excellent construct validity. Another computerized variant of the Corsi Block task appears as part of the CANTAB battery, normed for children through adults (Luciana \& Nelson 2002, Robbins et al. 1998). This does not really require mental manipulation. Bialystok's lab has developed a version that requires reordering (hence manipulation; Feng et al. 2007).

In the Self-Ordered Pointing task devised by Petrides (Petrides et al. 1993, Petrides \& Milner 1982), subjects see from 3 to 12 items (which might be line drawings, abstract designs, or boxes containing rewards) and are asked to touch one item at a time, in any order, without repeating a choice, making sure to touch all. When rewards are hidden, subjects get feedback after each choice because after having found the reward in a box once, the box will be empty for the rest of that trial. Remembering which items you have touched by their identity is tested by items that are each different from one another, their locations randomly scrambled after each reach (computerized by Diamond et al. 2004). Remembering which items you have touched by their spatial location is tested by using identical items that remain stationary (e.g., Diamond et al. 1997, Wiebe et al. 2010). The CANTAB battery offers a computerized version of the spatial-identity version. Although this task undoubtedly depends on dorsolateral prefrontal cortex [as studies with lesioned monkeys (Petrides 1995), brain-damaged human adults (Owen et al. 1996), and functional neuroimaging in healthy adults (Petrides et al. 1993) have clearly shown], it is not sensitive to the level of dopamine in dorsolateral prefrontal cortex (Collins et al. 1998; Diamond et al. 1997, 2004), although other EF tasks that depend on dorsolateral prefrontal cortex are sensitive to that.

To study WM, researchers often use complex span tasks, also called WM span tasks, such as counting span or reading span (Barrouillet et al. 2009, Case 1995, Conway et al. 2005, Daneman \& Carpenter 1980), but since these tasks often require more subcomponents of EFs than just holding information in mind and manipulating it, they are really EF measures rather than measures of the working-memory subcomponent alone. N-back tasks (also called AX Continuous Performance Tasks, or AX-CPTs) are also often used to assess WM (Owen et al. 2005, Verhaeghen \& Basak 2005), although they too require high levels of selective and sustained attention. It would probably cause less confusion if all of these measures were called EF tasks.

\section{Development of Working Memory}

The ability to hold information in mind develops very early; even infants and young children can hold one or two things in mind for quite a long time (Diamond 1995, Nelson et al.

2012). Infants of only 9 to 12 months can update the contents of their WM, as seen on tasks 
such as A-not-B (Bell \& Cuevas 2012, Diamond 1985). However, being able to hold many things in mind or do any kind of mental manipulation (e.g., reordering mental representations of objects by size) is far slower to develop and shows a prolonged developmental progression (Cowan et al. 2002, 2011; Crone et al. 2006; Davidson et al. 2006; Luciana et al. 2005).

WM declines during aging (e.g., Fiore et al. 2012, Fournet et al. 2012). Much of that appears to be due to declining inhibitory control making older adults more vulnerable to proactive and retroactive interference (Hedden \& Park 2001, Solesio-Jofre et al. 2012) and to distraction (Rutman et al. 2010, Zanto \& Gazzaley 2009). Remember that young children, too, are disproportionately challenged by inhibition compared to young adults (Davidson et al. 2006). Improved ability to inhibit interference appears critical to age-related improvements in WM in children (Hale et al. 1997), just as impaired ability to inhibit interference may underlie WM decline in older adults.

Decline in WM with aging and improvement in WM during development are also highly correlated with decline in speed of processing with aging and its improvement during early development (older adults: Rozas et al. 2008, Salthouse 1992, Zimprich \& Kurtz 2012; children: Case et al. 1982, Fry \& Hale 2000). How to understand the relation between speed of processing and EFs is controversial; the direction of causality might go either way, or a third factor might be causal for both and hence their correlation (Diamond 2002).

\section{COGNITIVE FLEXIBILITY}

Cognitive flexibility (the third core EF) builds on the other two and comes in much later in development (Davidson et al. 2006, Garon et al. 2008). One aspect of cognitive flexibility is being able to change perspectives spatially (e.g., "What would this look like if I viewed it from a different direction?") or interpersonally (e.g., "Let me see if I can see this from your point of view"). To change perspectives, we need to inhibit (or deactivate) our previous perspective and load into WM (or activate) a different perspective. It is in this sense that cognitive flexibility requires and builds on inhibitory control and WM. Another aspect of cognitive flexibility involves changing how we think about something (thinking outside the box). For example, if one way of solving a problem isn't working, can we come up with a new way of attacking this or conceiving of this that hadn't been considered before?

Cognitive flexibility also involves being flexible enough to adjust to changed demands or priorities, to admit you were wrong, and to take advantage of sudden, unexpected opportunities. Suppose you were planning to do $X$, but an amazing opportunity arose to do $Y$ : Do you have the flexibility to take advantage of serendipity?

When a student isn't grasping a concept, we often blame the student: "If only the student were brighter, he or she would have grasped what I'm trying to teach." We could be flexible and consider a different perspective: "What might I, the teacher, do differently? How can I present the material differently, or word the question differently, so this student can succeed?" 
There is much overlap between cognitive flexibility and creativity, task switching, and set shifting. Cognitive flexibility is the opposite of rigidity.

\section{Representative Psychological Tasks Used to Assess Cognitive Flexibility}

A family of tasks that taps cognitive flexibility includes design fluency (also called the unusual uses task), verbal fluency, and category (or semantic) fluency. You might be asked, for example, how many uses you can think of for a table or how many words you can think of that begin with the letter F, or you might be asked to alternate between the names of animals and the names of foods (Baldo et al. 2001, Baldo \& Shimamura 1997, Chi et al. 2012, Van der Elst et al. 2011). First the most common answers come to mind, such as you can eat or write on a table, but then more flexibly minded or creative people can come up with other uses such as dancing on a table, getting under it to stay dry, standing it on its side and using it as shield, chopping it up for firewood, or using it as a percussion instrument.

Cognitive flexibility is often investigated using any of a wide array of task-switching and set-shifting tasks. The oldest of these is probably the Wisconsin Card Sorting Task (Milner 1964, Stuss et al. 2000), one of the classic tests of prefrontal cortex function. Each card in this test can be sorted by color, shape, or number. The task for the participant is to deduce the correct sorting criterion on the basis of feedback and to flexibly switch sorting rules whenever the experimenter gives feedback that the sorting criterion has changed.

Most task-switching paradigms involve two tasks. Those tasks might be indicating whether (a) a letter is a vowel or consonant, (b) a number is even or odd (e.g., Monsell 2003), (c) a stimulus is on the left or right or in the upper or lower quadrant (e.g., Meiran 1996), or (d) a stimulus is one color or another or one shape or another (e.g., Allport \& Wylie 2000). Most task-switching tasks involve pressing a key on the right or left, with each key mapped to one feature of each task (e.g., left might be for a consonant or an even number and right for a vowel or an odd number). The stimuli in most task-switching tasks are bivalent, that is, they have a feature relevant to each of the two tasks, and the correct response for one task is incorrect for the other (e.g., for the stimulus "A2," the correct response for the letter task would be to press right because A is a vowel, whereas the correct response for the number task would be to press left because 2 is an even number).

Zelazo and colleagues developed perhaps the simplest possible test of task switching (Zelazo et al. 1996, 2003). The stimuli are bivalent, and the correct response for one task is incorrect for the other, but only one switch occurs during the entire test [called the Dimensional Change Card Sort Test (DCCS)]. First, one is to sort all six cards by one dimension (color or shape), and then one is to sort all the cards according to the other dimension. Memory demands are intentionally minimized by an illustration at each response location of the features mapped to that response and by the experimenter reminding the child of the current sorting criterion on each trial. Children of 3 years can flawlessly sort by either color or shape, but fail to switch even though they know the other dimension is now relevant and they know the rules for sorting by it. Errors seem to occur because of difficulty in inhibiting or overcoming what might be termed "attentional inertia," the tendency to continue to focus attention on what had previously been relevant (Kirkham et al. 2003, Kloo $\&$ Perner 2005; recently modeled by Chatham et al. 2012). Once a child of 3 has focused on 
the "redness" of a red truck, it's difficult for the child to switch mindsets and focus on its "truckness." The child gets stuck in the previous way of thinking about the stimuli. Indeed, in young children, activation in dorsolateral prefrontal cortex is first driven by the previous trial's rule (Wendelken et al. 2012), much as noted above for the neuronal population vector in motor cortex (Georgopoulos et al. 1989), requiring that the prepotent tendency be inhibited.

That inertial tendency never completely disappears. Traces of it can be seen in the heightened reaction times of healthy, young adults when required to switch and respond on the basis of another dimension (e.g., Diamond \& Kirkham 2005, Monsell \& Driver 2000). No matter how much warning adults are given about which dimension will be relevant on the upcoming trial, how long the period between the forewarning and when the stimulus appears, or how long the period between trials, adults are slower to respond on trials where the relevant dimension switches than on nonswitch trials (Allport \& Wylie 2000, Meiran 1996, Rogers \& Monsell 1995). What drives this difference on switch and nonswitch trials is the subset of switch trials where the rule changes (which aspect of the stimulus is relevant changes) but where you should respond does not change. We seem to like everything to stay the same (rule and response site) or everything to change (if the rule changes, we're faster if the response site also changes; Crone et al. 2006, Diamond 2009).

Many other tasks tap similar inertial tendencies such as ambiguous figures where, depending on how you look at a line drawing, you might see a vase or the profiles of two faces, for example. Even when informed of the alternatives in an ambiguous figure, 3-year-olds remain stuck in their initial way of perceiving it; they cannot switch perspectives, just as they cannot switch sorting dimensions (Gopnik \& Rosati 2001). By age 41/2 to 5 years, most children can see both figures in an ambiguous figure and can switch sorting dimensions on the DCCS task (Diamond 2002).

Not until 7 to 9 years of age, however, can children switch flexibly on a trial-by-trial basis as all standard task-switching paradigms require (Davidson et al. 2006, Gupta et al. 2009). For adults, it is trivially easy to execute a block of one task and a block of the other. Even when one of the tasks asks you to do something counter to your prepotent tendency it is not that hard for adults to get in the groove of doing that over a block of trials. Indeed, adults show no cost at all of always responding across a block of trials on the side opposite to where a stimulus appears (Davidson et al. 2006, Lu \& Proctor 1995). It's not that demanding for adults to keep doing what they've been doing, even if it is counterintuitive or counter to their initial inclination; after a while it requires little top-down control. What's far more difficult is switching back and forth between mental sets. Simply put, it is easier to inhibit a dominant response all the time than only some of the time. Cognitive flexibility, overcoming inertial tendencies so you can switch back and forth between mental sets or ways of thinking about the stimuli, is one of the most demanding of the EFs.

A Flanker effect 6 to 10 times larger than what all labs report is obtained simply by having subjects switch between focusing on the center stimulus and focusing on the Flankers, assessing the Flanker effect only on trials where subjects are to focus on the same place they focused on the previous trial (i.e., nonswitch trials). Moreover, in the mixed block the 
Flanker effect (on nonswitch trials) is robust in the face of variations in stimulus parameters (such as size), unlike the Flanker effect in the standard single-task block (Munro et al. 2006).

\section{Development of Cognitive Flexibility}

A very easy type of switching involves continuing to focus on the same dimension (on the same aspect of the stimuli) but reversing the stimulus-response mappings. This is called reversal, within-dimension switching, or intradimensional shifting (e.g., Kendler \& Kendler 1959, Kendler et al. 1972, Roberts et al. 1988). For example, in Task 1 you might press left for circle and right for triangle, while in Task 2 that would be reversed, so you'd press right for circle and left for triangle. Children only $2 \frac{1}{2}$ years of age can succeed at such tasks (Brooks et al. 2003, Perner \& Lang 2002). The ability to change where you respond (switch stimulus-response mappings, as on reversal tasks) develops earlier than the ability to change how you think about the stimuli or change what aspect of the stimuli you attend to. Although children cannot usually succeed at the DCCS task until $4 \frac{1}{2}$ to 5 years of age (see above), if color is a property of the background of the card rather than of the shape pictured on the card (so a truck is always a truck and the background is always red, instead of the shape itself being colored so that from one perspective a truck is a truck but from another perspective it is a red thing), children can succeed by 3 to $3 \frac{1}{2}$ years of age (Diamond et al. 2005, Kloo \& Perner 2005).

Task switching improves during child development and declines during aging (Cepeda et al. 2001, Kray 2006). Older adults slow down on a mixed block (where on any trial it might be Task 1 or Task 2), hence the difference in their speed on mixed blocks versus single-task blocks is much greater than that of young adults, but unlike young adults they are almost as slow on repeat trials in a mixed block as on switch trials (Kray \& Lindenberger 2000, Mayr \& Liebscher 2001, Meiran \& Gotler 2001). Children show much larger differences in their speed (like older adults) and accuracy (unlike older adults) on mixed blocks versus singletask blocks than do young adults (Cepeda et al. 2001, Cohen et al. 2001).

Young children and older adults tend to exercise EFs in response to environmental demands (reactively), whereas older children and young adults tend to be more planful and anticipatory (recruiting EFs proactively; Czernochowski et al. 2010, Karayanidis et al. 2011, Munakata et al. 2012).

\section{A HIGHER-ORDER EXECUTIVE FUNCTION: RELATIONAL REASONING/ LOGICAL REASONING/FLUID INTELLIGENCE}

Fluid intelligence is the ability to reason, problem solve, and to see patterns or relations among items (Ferrer et al. 2009). It includes both inductive and deductive logical reasoning. It involves being able to figure out the abstract relations underlying analogies. It is synonymous with the reasoning and problem-solving subcomponents of EFs (see Figure 4). No surprise then that measures of fluid intelligence [e.g., Raven's Matrices (Raven 2000)] are highly correlated with independent measures of EFs (Conway et al. 2003, Duncan et al. 2008, Kane \& Engle 2002, Roca et al. 2010). 


\section{DIFFERENCES AND SIMILARITIES BETWEEN EXECUTIVE FUNCTIONS AND RELATED TERMS}

Self-regulation refers to processes that enable us to maintain optimal levels of emotional, motivational, and cognitive arousal (Eisenberg et al. 2007, Liew 2011). It refers primarily to control and regulation of one's emotions (Eisenberg et al. 2010, Mischel \& Ayduk 2002) and overlaps substantially with inhibitory control (see Figure 4). EF researchers have historically focused more on thoughts, attention, and actions [and hence more on lateral prefrontal cortex (dorso- and ventrolateral prefrontal)]; self-regulation researchers have focused more on emotions [and hence more on medial prefrontal cortex (especially orbitofrontal) and on the parasympathetic nervous system]. EF researchers have addressed emotions primarily as problems to be inhibited; self-regulation researchers also embrace the importance of motivation and interest as helpful emotional responses for achieving one's goals (Blair \& Diamond 2008). Historically, self-regulation has been assessed through (a) adult ratings of children's behavior observed in real-world settings such as home or school, and (b) observation of children's behavior when they have to delay gratification in an emotionally laden "hot" situation (Mischel et al. 1989) or in a frustrating situation (Kochanska et al. 2009). Historically, EFs have been assessed directly from children's behavior, but on arbitrary laboratory-based tests far removed from the real world in fairly emotionally neutral "cool" situations.

Effortful control (Rothbart \& Bates 2006) refers to an aspect of temperament. It is an innate predisposition to exercise self-regulation with ease (e.g., easily able to slow down or lower one's voice), perhaps even being too regulated (lacking in spontaneity) versus finding selfregulation difficult or less natural. It is usually assessed by parental report (Goldsmith 1996, Rothbart et al. 2001).

Executive attention (Posner \& DiGirolamo 1998) refers to the top-down regulation of attention. It is usually assessed using measures of selective attention such as the Flanker task (Fan et al. 2002, Rueda et al. 2005). Much confusion has been engendered by the overly broad use of the term executive attention to apply to such skills as WM capacity (Engle 2002) and response inhibition or the resolution of response conflict (as in a Simon-type task; Jones et al. 2003).

\section{IT IS NOT ALWAYS BENEFICIAL TO EXERT EXECUTIVE FUNCTIONS OR TOP-DOWN CONTROL}

We need lateral prefrontal cortex (EFs) when learning something new. When something is new, those who recruit lateral prefrontal cortex most often perform best (Duncan \& Owen 2000, Poldrack et al. 2005). However, after something is no longer new, those who perform best often recruit lateral prefrontal cortex least (Chein \& Schneider 2005, Garavan et al. 2000, Landau et al. 2007, Milham et al. 2003). When you are really good at something, you are using top-down control very little if at all (as in Zen in the Art of Archery; Herrigel 1999). Indeed, when you are truly good at something, thinking about what you are doing often gets in the way of performing well. Thus, early in training, disrupting lateral prefrontal 
cortex function impairs task performance, but disrupting lateral prefrontal function after a task is familiar can improve performance (Miller et al. 2003).

Phylogenetically older brain regions have had far longer to perfect their functioning; they can subserve task performance ever so much more efficiently than can prefrontal cortex. You might say that your goal in trying to master something is to have it become so well learned that prefrontal cortex and EFs are no longer needed for it. Instead, performance is handed off to older regions that have had thousands of more years of evolutionary time to perfect their functioning and can subserve task performance ever so much more efficiently than can prefrontal. A child may know intellectually (at the level of prefrontal cortex) that $\mathrm{s} /$ he should not hit another, but in the heat of the moment if that knowledge has not become automatic (passed on from prefrontal to subcortical regions), the child will hit another (though if asked, s/he knows not to do that). It's the difference between knowing what you should do at an intellectual level and having it become second nature. The way something becomes second nature or automatic is through repeated practice. This is consistent with what Ericsson has repeatedly found to be key for being truly excellent at anything (e.g., Ericsson et al. 2009), i.e., hours and hours of practice.

\section{CANARY IN THE COAL MINE: EXECUTIVE FUNCTIONS AS AN EARLY WARNING SYSTEM}

EFs and prefrontal cortex are the first to suffer, and suffer disproportionately, if something is not right in your life. They suffer first, and most, if you are stressed (Arnsten 1998, Liston et al. 2009, Oaten \& Cheng 2005), sad (Hirt et al. 2008, von Hecker \& Meiser 2005), lonely (Baumeister et al. 2002, Cacioppo \& Patrick 2008, Campbell et al. 2006, Tun et al. 2012), sleep deprived (Barnes et al. 2012, Huang et al. 2007), or not physically fit (Best 2010, Chaddock et al. 2011, Hillman et al. 2008). Any of these can cause you to appear to have a disorder of EFs, such as ADHD, when you do not. You can see the deleterious effects of stress, sadness, loneliness, and lack of physical health or fitness at the physiological and neuroanatomical level in prefrontal cortex and at the behavioral level in worse EFs (poorer reasoning and problem solving, forgetting things, and impaired ability to exercise discipline and self-control).

If we want schoolchildren, workers, or business executives to have better attention and concentration, be better able to reason and problem solve, we cannot ignore stresses in their lives. Each schoolchild and each employee will do better if that individual's passionate interests can be engaged, energizing the person. They will perform better and show better EFs if they feel they are in a supportive community they can count on. They will perform better and show better EFs if their bodies are strong and healthy. A school or corporation that ignores students' or employees' emotional, social, or physical needs is likely to find that those unmet needs will work against achieving performance goals.

\section{TRAINING AND PRACTICE IMPROVE EXECUTIVE FUNCTIONS}

EFs can be improved (Diamond \& Lee 2011, Klingberg 2010). The strongest evidence for an activity improving children's EFs exists for CogMed@ computerized training (Bergman 
Nutley et al. 2011, Holmes et al. 2009, Klingberg et al. 2005, Thorell et al. 2009), a combination of computerized and interactive games (Mackey et al. 2011), task-switching computerized training (Karbach \& Kray 2009), Taekwondo traditional martial arts (Lakes \& Hoyt 2004), and two add-ons to school curricula, Promoting Alternative Thinking Strategies (PATHS; Riggs et al. 2006) and the Chicago School Readiness Project (CSRP; Raver et al. 2008, 2011). The above-referenced studies used random assignment and included an active control group and pre- and post-intervention measures; they found convincing transfer to more than one objective measure of EFs on which the children had not been trained. Studies that have thus far looked at the benefits to children's EFs from aerobics (Davis et al. 2011, Kamijo et al. 2011), mindfulness (Flook et al. 2010), yoga (Manjunath \& Telles 2001), Tools of the Mind early childhood curriculum (Diamond et al. 2007), and Montessori curriculum (Lillard \& Else-Quest 2006) have found positive results but lacked one or more of the above design features. With adults, the focus has most often been on computerized training, especially of WM. Recent reviews of such computerized EF training with adults are cautiously optimistic but note important design flaws (Morrison \& Chein 2011, Shipstead et al. 2012).

A few principles hold regardless of the EF program or intervention:

1. The children most behind on EFs (including disadvantaged children) benefit the most from any EF intervention or program (Flook et al. 2010, Karbach \& Kray 2009, Lakes \& Hoyt 2004). Hence, early EF training might level the playing field by reducing social disparities in EFs, thus heading off social disparities in academic achievement and health (O'Shaughnessy et al. 2003).

2. EF training appears to transfer, but transfer from computerized $\mathrm{WM}$ or reasoning training has been narrow (e.g., computer training on spatial WM transfers to other measures of spatial WM but not to visual WM or other EF subcomponents; Bergman Nutley et al. 2011). EF gains from training in task switching (Karbach \& Kray 2009), traditional martial arts (Lakes \& Hoyt 2004) and school curricula (Raver et al. 2011, Riggs et al. 2006) have been wider, perhaps because the programs address EFs more globally. For example, training task switching (which arguably requires all three core EFs) transferred not only to an untrained taskswitching task, but also to inhibition (Stroop interference), verbal and nonverbal WM, and reasoning (Karbach \& Kray 2009).

3. EF demands need to be continually incrementally increased or few gains are seen (Bergman Nutley et al. 2011, Holmes et al. 2009, Klingberg et al. 2005). There may be two reasons for that. (a) If difficulty doesn't increase, the activity becomes boring and people lose interest. (Which raises a general question about the appropriateness of a control group where difficulty does not increase, if that means the groups also differ in their sustained interest.) (b) You need to keep pushing yourself to do better or you stop improving. Similarly, Ericsson et al. (2009) emphasize that the practice that leads to expertise at anything consists of trying to master what is just beyond your current level of competence and comfort. 
4. Repeated practice is key. Whether EF gains are seen depends on the amount of time spent doggedly working on those skills, pushing oneself to improve (Klingberg et al. 2005). School curricula shown to improve EFs train and challenge EFs throughout the day, embedding that in all activities, not only in a module (which may also have the benefit of varying the content and kind of EF practice; Diamond et al. 2007, Lillard \& Else-Quest 2006, Riggs et al. 2006).

5. The largest differences between intervention groups and controls are consistently found on the most demanding EF tasks and task conditions. It is often only in pushing the limits of children's EF skills that group differences emerge (Davis et al. 2011, Diamond et al. 2007, Manjunath \& Telles 2001). For example, in their first year of data collection, Farran \& Wilson (2011) found no EF benefits from Tools of the Mind, but their assessment tasks were plagued by ceiling and floor effects.

At any age across the life cycle EFs can be improved, including in the elderly and in infants. There has been much work with excellent results on improving EFs in the elderly by improving physical fitness (Erickson \& Kramer 2009, Voss et al. 2011). Increasingly, research is also showing promising results from computerized EF training with older adults (Lövdén et al. 2010, Richmond et al. 2011). Much but not all of the work on improving EFs in young adults has focused on computerized training (Morrison \& Chein 2011, Muraven 2010, Shipstead et al. 2012). Exposure to bilingual input has been one of the foci, though not the only focus, of work on accelerating the development of EFs in infants (Kovács \& Mehler 2009, Wass et al. 2011). [Bilingualism appears to accelerate EF development during childhood and preserve EFs longer during aging (e.g., Bialystok \& Viswanathan 2009), but its chief benefit appears to be in improving speed of processing. For example, bilingual older adults do not show a smaller Simon effect (i.e., do not show better inhibitory control on the task) but rather are faster on all trials (Bialystok et al. 2004).]

No one has yet looked at what distinguishes those who benefit from EF training from those who don't, other than the amount of practice and baseline EFs. We know little about whether benefits last or how long they might last, or about what dose or frequency is best. What factors affect how long benefits last? Are refresher or booster sessions needed, and if so at what intervals and for how long? Are different programs more beneficial at different ages? Who might benefit most from which activity? Does the optimal dose or frequency vary by age? These questions are particularly pressing because "interventions that achieve even small improvements in [inhibitory control] for individuals could shift the entire distribution of outcomes in a salutary direction and yield large improvements in health, wealth, and crime rate for a nation" (Moffitt et al. 2011, p. 2694).

In conclusion, EFs are critical for many of the skills that most people would agree will be important for success in the twenty-first century-such as creativity, flexibility, self-control, and discipline. EFs make it possible for us to mentally play with ideas, quickly and flexibly adapt to changed circumstances, take time to consider what to do next, resist temptations, stay focused, and meet novel, unanticipated challenges. 
We share with even simple organisms the ability to be conditioned (to be affected by our experience), and we, like them, come into the world with certain biological predispositions. However, we are able to hold in mind things we cannot see and to inhibit our predispositions and conditioned responses, however fragile and incomplete those abilities may be. We have the possibility to exercise choice and control over what we do. Now is an exciting time because we have the tools to answer many of the unresolved questions about EFs. Finding the answers to these questions is critical because the ability of our generation and succeeding ones to meet the world's challenges may depend on that.

\section{Acknowledgments}

I would like to express my gratitude to Silvia Bunge, Patti Reuter-Lorenz, Yuko Munakata, and Daphne Ling for extremely helpful comments on an earlier version of this manuscript. I would also like to express my gratitude for financial support from NIDA R01 \#DA019685 during the writing of this article.

\section{Glossary}

\section{Executive functions (EFs)}

Inhibition
(inhibitory
control)

Self-control

Working memory (WM)

Cognitive

flexibility

CANTAB

PATHS

CSRP a collection of top-down control processes used when going on automatic or relying on instinct or intuition would be ill-advised, insufficient, or impossible controlling one's attention, behavior, thoughts, and/or emotions to override a strong internal predisposition or external lure

the aspect of inhibitory control that involves resisting temptations and not acting impulsively or prematurely

holding information in mind and mentally working with it (e.g., relating one thing to another, using information to solve a problem) changing perspectives or approaches to a problem, flexibly adjusting to new demands, rules, or priorities (as in switching between tasks) Cambridge Neuropsychological Testing Automated Battery Promoting Alternative Thinking Strategies Chicago School Readiness Project

\section{LITERATURE CITED}

Alain C, Woods DL. Age-related changes in processing auditory stimuli during visual attention: evidence for deficits in inhibitory control and sensory memory. Psychol. Aging. 1999; 14:507-19. [PubMed: 10509703]

Alloway TP. Working memory, reading and mathematical skills in children with developmental coordination disorder. J. Exp. Child Psychol. 2007; 96:20-36. [PubMed: 17010988]

Alloway TP, Gathercole SE, Kirkwood H, Elliott J. The cognitive and behavioral characteristics of children with low working memory. Child Dev. 2009; 80:606-21. [PubMed: 19467014]

Alloway TP, Gathercole SE, Willis C, Adams A-M. A structural analysis of working memory and related cognitive skills in young children. J. Exp. Child Psychol. 2004; 87:85-106. [PubMed: 14757066] 
Allport, A.; Wylie, G. Task switching, stimulus-response bindings, and negative priming. In: Monsell, S.; Driver, J., editors. Control of Cognitive Processes: Attention and Performance XVII. MIT Press; Cambridge, MA: 2000. p. 35-70.

Anderson MC, Levy B. Suppressing unwanted memories. Curr. Dir. Psychol. Sci. 2009; 18:189-94.

Arnsten AFT. The biology of being frazzled. Science. 1998; 280:1711-12. [PubMed: 9660710]

Aron AR. From reactive to proactive and selective control: developing a richer model for stopping inappropriate responses. Biol. Psychiatry. 2011; 69:e55-68. [PubMed: 20932513]

Awh E, Anllo-Vento L, Hillyard SA. The role of spatial selective attention in working memory for locations: evidence from event-related potentials. J. Cogn. Neurosci. 2000; 12:840-47. [PubMed: 11054925]

Awh E, Jonides J. Overlapping mechanisms of attention and spatial working memory. Trends Cogn. Sci. 2001; 5:119-26. [PubMed: 11239812]

Baddeley AD, Hitch GJ. Developments in the concept of working memory. Neuropsychology. 1994; 8:485-93.

Bailey CE. Cognitive accuracy and intelligent executive function in the brain and in business. Ann. N. Y. Acad. Sci. 2007; 1118:122-41. [PubMed: 17717092]

Baldo JV, Shimamura AP. Letter and category fluency in patients with frontal lobe lesions. Neuropsychology. 1997; 12:259-67. [PubMed: 9556772]

Baldo JV, Shimamura AP, Delis DC, Kramer J, Kaplan E. Verbal and design fluency in patients with frontal lobe lesions. J. Int. Neuropsychol. Soc. 2001; 7:586-96. [PubMed: 11459110]

Baler RD, Volkow ND. Drug addiction: the neurobiology of disrupted self-control. Trends Mol. Med. 2006; 12:559-66. [PubMed: 17070107]

Band GP, van der Molen MW, Logan GD. Horse-race model simulations of the stop-signal procedure. Acta Psychol. (Amsterdam). 2003; 112:105-42.

Barch DM. The cognitive neuroscience of schizophrenia. Annu. Rev. Psychol. 2005; 1:321-53.

Barnes ME, Gozal D, Molfese DL. Attention in children with obstructive sleep apnoea: an eventrelated potentials study. Sleep Med. 2012; 13:368-77. [PubMed: 22425681]

Barr RA, Giambra LM. Age-related decrement in auditory selective attention. Psychol. Aging. 1990; 5:597-99. [PubMed: 2278686]

Barrouillet P, Gavens N, Vergauwe E, Gaillard V, Camos V. Working memory span development: a time-based resource-sharing model account. Dev. Psychol. 2009; 45:477-90. [PubMed: 19271832]

Baumeister RF, Twenge JM, Nuss CK. Effects of social exclusion on cognitive processes: anticipated aloneness reduces intelligent thought. J. Pers. Soc. Psychol. 2002; 83:817-27. [PubMed: 12374437]

Bell, MA.; Cuevas, K. Psychobiology of executive function in early development. In: McCardle, P.; Freund, L.; Griffin, JA., editors. Executive Function in Preschool Age Children: Integrating Measurement, Neurodevelopment and Translational Research. Am. Psychol. Assoc.; Washington, DC: 2012. In press

Bergman Nutley S, Söderqvist S, Bryde S, Thorell LB, Humphreys K, Klingberg T. Gains in fluid intelligence after training non-verbal reasoning in 4-year-old children: a controlled, randomized study. Dev. Sci. 2011; 14:591-601. [PubMed: 21477197]

Best JR. Effects of physical activity on children's executive function: contributions of experimental research on aerobic exercise. Dev. Rev. 2010; 30:331-551. [PubMed: 21818169]

Bialystok E, Craik FIM, Klein R, Mythili V. Bilingualism, aging, and cognitive control: evidence from the Simon task. Psychol. Aging. 2004; 19:290-303. [PubMed: 15222822]

Bialystok E, Viswanathan M. Components of executive control with advantages for bilingual children in two cultures. Cognition. 2009; 112:494-500. [PubMed: 19615674]

Blair C, Diamond A. Biological processes in prevention and intervention: the promotion of selfregulation as a means of preventing school failure. Dev. Psychopathol. 2008; 20:899-911. [PubMed: 18606037]

Blair C, Razza RP. Relating effortful control, executive function, and false-belief understanding to emerging math and literacy ability in kindergarten. Child Dev. 2007; 78:647-63. [PubMed: 17381795] 
Bodrova, E.; Leong, DJ. Tools of the Mind: The Vygotskian Approach to Early Childhood education. Merrill/Prentice Hall; New York: 2007.

Borella E, Carretti B, Pelgrina S. The specific role of inhibition in reading comprehension in good and poor comprehenders. J. Learn. Disabil. 2010; 43:541-52. [PubMed: 20606207]

Broidy LM, Nagin DS, Tremblay RE, Brame B, Dodge KA, Fergusson DE. Developmental trajectories of childhood disruptive behaviors and adolescent delinquency: a six-site cross-national study. Dev. Psychol. 2003; 30:222-45. [PubMed: 12661883]

Brooks P, Hanauer JB, Padowska B, Rosman H. The role of selective attention in preschoolers' rule use in a novel dimensional card sort. Cogn. Dev. 2003; 117:1-21.

Brown TE, Landgraf JM. Improvements in executive function correlate with enhanced performance and functioning and health-related quality of life: evidence from 2 large, double-blind, randomized, placebo-controlled trials in ADHD. Postgrad. Med. 2010; 122:42-51. [PubMed: 20861587]

Bruner, JS.; Olver, RR.; Greenfield, PM. Studies in Cognitive Growth: A Collaboration at the Center for Cognitive Studies. Wiley; New York: 1966.

Bunge SA, Dudukovic NM, Thomason ME, Vaidya CJ, Gabrieli JDE. Immature frontal lobe contributions to cognitive control in children: evidence from fMRI. Neuron. 2002; 33:301-11. [PubMed: 11804576]

Burgess, PW.; Simons, JS. Theories of frontal lobe executive function: clinical applications. In: Halligan, PW.; Wade, DT., editors. Effectiveness of Rehabilitation for Cognitive Deficits. Oxford Univ. Press; New York: 2005. p. 211-31.

Cacioppo J, Patrick W. Loneliness: Human Nature and the Need for Social Connection. 2008NortonNew York Summarizes pioneering research on startling and profound effects of loneliness.

Campbell WK, Krusemark EA, Dyckman KA, Brunell AB, McDowell JE, et al. A magnetoencephalography investigation of neural correlates for social exclusion and self-control. Soc. Neurosci. 2006; 1:124-34. [PubMed: 18633781]

Carr LA, Nigg JT, Henderson JM. Attentional versus motor inhibition in adults with attention-deficit/ hyperactivity disorder. Neuropsychology. 2006; 20:430-41. [PubMed: 16846261]

Case, R. Capacity-based explanations of working memory growth: a brief history and reevaluation. In: Weinert, FE.; Schneider, W., editors. Memory Performance and Competencies: Issues in Growth and Development. Erlbaum; Mahwah, NJ: 1995. p. 23-44.

Case R, Kurland DM, Goldberg J. Operational efficiency and the growth of short-term memory span. J. Exp. Child Psychol. 1982; 33:386-404.

Casey, BJ.; Siegler, RS.; McClelland, JL. Development and disruption of inhibitory mechanisms of attention. Mechanisms of Cognitive Development: The Carnegie Symposium on Cognition; Hillsdale, NJ: Erlbaum; 2001. p. 327-49.

Cepeda NJ, Kramer AF, Gonzalez de Sather JC. Changes in executive control across the life span: examination of task-switching performance. Dev. Psychol. 2001; 37:715-30. [PubMed: 11552766]

Cepeda NJ, Munakata Y. Why do children perseverate when they seem to know better: graded working memory, or directed inhibition? Psychon. Bull. Rev. 2007; 14:1058-65. [PubMed: 18229475]

Chaddock L, Hillman CH, Buck SM, Cohen NJ. Aerobic fitness and executive control of relational memory in preadolescent children. Med. Sci. Sports Exerc. 2011; 43:344-49. [PubMed: 20508533]

Chatham $\mathrm{CH}$, Yerys BE, Munakata Y. Why won't you do what I want? The informative failures of children and models. Cogn. Dev. 2012 In press.

Chein JM, Schneider W. Neuroimaging studies of practice-related change: fMRI and meta-analytic evidence of a domain-general control network for learning. Cogn. Brain Res. 2005; 25:607-23

Chi YK, Kim TH, Han JW, Lee SB, Park JH, et al. Impaired design fluency is a marker of pathological cognitive aging: results from the Korean longitudinal study on health and aging. Psychiatry Invest. 2012; 9:59-64.

Cohen JR, Berkman ET, Lieberman MD. Ventrolateral PFC as a self-control muscle and how to use it without trying. Oxford Handb. Frontal Lobe Funct. 2012 In press. 
Cohen, S.; Bixenman, M.; Meiran, N.; Diamond, A. Task switching in children. Presented at S. Carolina Bicentenn. Symp. Attention; Columbia: Univ. S. Carolina; 2001.

Collins A, Koechlin E. Reasoning, learning, and creativity: frontal lobe function and human decisionmaking. PLoS Biol. 2012; 10:e1001293. [PubMed: 22479152]

Collins P, Roberts AC, Dias R, Everitt BJ, Robbins TW. Perseveration and strategy in a novel spatial self-ordered task for nonhuman primates: effect of excitotoxic lesions and dopamine depletions of the prefrontal cortex. J. Cogn. Neurosci. 1998; 10:332-54. [PubMed: 9869708]

Conway ARA, Engle RW. Working memory and retrieval: a resource-dependent inhibition model. J. Exp. Psychol.: Gen. 1994; 123:354-73. [PubMed: 7996121]

Conway ARA, Kane MJ, Bunting MF, Hambrick DZ, Wilhelm O, Engle RW. Working memory span tasks: a methodological review and user's guide. Psychon. Bull. Rev. 2005; 12:769-86. [PubMed: 16523997]

Conway ARA, Kane MJ, Engle RW. Working memory capacity and its relation to general intelligence. Trends Cogn. Sci. 2003; 7:547-52. [PubMed: 14643371]

Cowan N, AuBuchon AM, Gilchrist AL, Ricker TJ, Saults JS. Age differences in visual working memory capacity: not based on encoding limitations. Dev. Sci. 2011; 14:1066-74. [PubMed: 21884322]

Cowan N, Saults JS, Elliot EM. The search for what is fundamental in the development of working memory. Adv. Child Dev. Behav. 2002; 29:1-49. [PubMed: 11957571]

Cragg L, Nation K. Go or no-go? Developmental improvements in the efficiency of response inhibition in mid-childhood. Dev. Sci. 2008; 11:819-27. [PubMed: 19046150]

Crescioni AW, Ehrlinger J, Alquist JL, Conlon KE, Baumeister RF, et al. High trait self-control predicts positive health behaviors and success in weight loss. J. Health Psychol. 2011; 16:750-59. [PubMed: 21421645]

Crone EA, Wendelken C, Donohue SE, van Leijenhorst L, Bunge SA. Neurocognitive development of the ability to manipulate information in working memory. Proc. Natl. Acad. Sci. USA. 2006; 103:9315-20. [PubMed: 16738055]

Czernochowski D, Nessler D, Friedman D. On why not to rush older adults—relying on reactive cognitive control can effectively reduce errors at the expense of slowed responses. Psychophysiology. 2010; 47:637-46. [PubMed: 20136730]

Daneman M, Carpenter P. Individual differences in working memory and reading. J. Verbal Learn. Verbal Behav. 1980; 19:450-66.

Darowski ES, Helder E, Zacks RT, Hasher L, Hambrick DZ. Age-related differences in cognition: the role of distraction control. Neuropsychology. 2008; 22:638-44. [PubMed: 18763883]

Davidson MC, Amso D, Anderson LC, Diamond A. Development of cognitive control and executive functions from 4-13 years: evidence from manipulations of memory, inhibition, and task switching. Neuropsychologia. 2006; 44:2037-78. [PubMed: 16580701]

Davis CL, Tomporowski PD, McDowell JE, Austin BP, Miller PH, et al. Exercise improves executive function and achievement and alters brain activation in overweight children: a randomized, controlled trial. Health Psychol. 2011; 30:91-98. [PubMed: 21299297]

Davis JC, Marra CA, Najafzadeh M, Lui-Ambrose T. The independent contribution of executive functions to health related quality of life in older women. BMC Geriatr. 2010; 10:16-23. [PubMed: 20359355]

de Jong R, Coles MGH, Logan GD. Strategies and mechanisms in nonselective and selective inhibitory motor control. J. Exp. Psychol.: Hum. Percept. Perform. 1995; 21:498-511. [PubMed: 7790830]

Denson TF, Pederson WC, Friese M, Hahm A, Roberts L. Understanding impulsive aggression: Angry rumination and reduced self-control capacity are mechanisms underlying the provocationaggression relationship. Pers. Soc. Psychol. Bull. 2011; 37:850-62. [PubMed: 21421767]

D'Esposito M, Postle BR, Ballard D, Lease J. Maintenance versus manipulation of information held in working memory: an event-related fMRI study. Brain Cogn. 1999; 41:66-86. [PubMed: 10536086]

Diamond A. Development of the ability to use recall to guide action, as indicated by infants' performance on A-not-B. Child Dev. 1985; 56:868-83. [PubMed: 4042750] 
Diamond A. Developmental time course in human infants and infant monkeys, and the neural bases, of inhibitory control in reaching. Ann. N. Y. Acad. Sci. 1990; 608:637-76. [PubMed: 2075965]

Diamond, A. Neuropsychological insights into the meaning of object concept development. In: Carey, S.; Gelman, R., editors. The Epigenesis of Mind: Essays on Biology and Cognition. Erlbaum; Hillsdale, NJ: 1991. p. 67-110.

Diamond A. Evidence of robust recognition memory early in life even when assessed by reaching behavior. J. Exp. Child Psychol. 1995; 59:419-56. [PubMed: 7622987]

Diamond, A. Normal development of prefrontal cortex from birth to young adulthood: cognitive functions, anatomy, and biochemistry. In: Stuss, DT.; Knight, RT., editors. Principles of Frontal Lobe Function. Oxford Univ. Press; London: 2002. p. 466-503.

Diamond A. Attention-deficit disorder (attention-deficit/hyperactivity disorder without hyperactivity): a neurobiologically and behaviorally distinct disorder from attention-deficit/hyperactivity disorder (with hyperactivity). Dev. Psychopathol. 2005; 17:807-25. [PubMed: 16262993]

Diamond A. All or none hypothesis: a global-default mode that characterizes the brain and mind. Dev. Psychol. 2009; 45:130-38. [PubMed: 19209996]

Diamond A, Barnett WS, Thomas J, Munro S. Preschool program improves cognitive control. Science. 2007; 318:1387-88. [PubMed: 18048670]

Diamond A, Briand L, Fossella J, Gehlbach L. Genetic and neurochemical modulation of prefrontal cognitive functions in children. Am. J. Psychiatry. 2004; 16:125-32. [PubMed: 14702260]

Diamond A, Carlson SM, Beck DM. Preschool children's performance in task switching on the dimensional change card sort task: Separating the dimensions aids the ability to switch. Dev. Neuropsychol. 2005; 28:689-729. [PubMed: 16144433]

Diamond A, Kirkham NZ. Not quite as grown-up as we like to think: parallels between cognition in childhood and adulthood. Psychol. Sci. 2005; 16:291-97. [PubMed: 15828976]

Diamond A, Kirkham NZ, Amso D. Conditions under which young children can hold two rules in mind and inhibit a prepotent response. Dev. Psychol. 2002; 38:352-62. [PubMed: 12005379]

Diamond A, Lee K. Interventions and programs demonstrated to aid executive function development in children 4-12 years of age. Science. 2011; 333:959-64. [PubMed: 21852486] The only review of EF interventions with children thus far; reviews diverse approaches.

Diamond A, Prevor M, Callender G, Druin DP. Prefrontal cortex cognitive deficits in children treated early and continuously for PKU. Monogr. Soc. Res. Child Dev. 1997; 62(Ser. No. 252):1-7. [PubMed: 9353949]

Duncan GJ, Dowsett CJ, Claessens A, Magnuson K, Huston AC, et al. School readiness and later achievement. Dev. Psychol. 2007; 43:1428-46. [PubMed: 18020822]

Duncan J, Owen AM. Common regions of the human frontal lobe recruited by diverse cognitive demands. Trends Neurosci. 2000; 23:475-83. [PubMed: 11006464]

Duncan J, Parr A, Woolgar A, Thompson R, Bright P, et al. Goal neglect and Spearman's g: competing parts of a complex task. J. Exp. Psychol.: Gen. 2008; 137:131-48. [PubMed: 18248133]

Eakin L, Minde K, Hechtman L, Ochs E, Krane E, et al. The marital and family functioning of adults with ADHD and their spouses. J. Attention Disord. 2004; 8:1-10.

Egner T, Hirsch J. Cognitive control mechanisms resolve conflict through cortical amplification of task-relevant information. Nat. Neurosci. 2005; 8:1784-90. [PubMed: 16286928]

Eigsti I, Zayas V, Mischel W, Shoda Y, Ayduk O, et al. Predicting cognitive control from preschool to late adolescence and young adulthood. Psychol. Sci. 2006; 17:478-84. [PubMed: 16771797]

Eisenberg, N.; Hofer, J.; Vaughan, C. Effortful control and its socioemotional consequences. In: Gross, JJ., editor. Handbook of Emotion Regulation. Guilford; New York: 2007. p. 287-306.

Eisenberg N, Spinrad TL, Eggum ND. Emotion-related self-regulation and its relation to children's maladjustment. Annu. Rev. Clin. Psychol. 2010; 6:495-525. [PubMed: 20192797]

Eldreth DA, Patterson MD, Porcelli AJ, Biswal BB, Rebbechi D, Rypma B. Evidence for multiple manipulation processes in prefrontal cortex. Brain Res. 2006; 1123:145-56. [PubMed: 17070786]

Engelhardt PE, Nigg JT, Carr LA, Ferreira F. Cognitive inhibition and working memory in attentiondeficit/hyperactivity disorder. J. Abnorm. Psychol. 2008; 117:591-605. [PubMed: 18729611] 
Engle RW. Working memory capacity as executive attention. Curr. Dir. Psychol. Sci. 2002; 11:19-23.

Engle, RW.; Kane, MJ. Executive attention, working memory capacity, and a two-factor theory of cognitive control. In: Ross, B., editor. The Psychology of Learning and Motivation. Elsevier; New York: 2004. p. 145-99.

Erickson KL, Kramer AF. Aerobic exercise effects on cognitive and neural plasticity in older adults. Br. J. Sports Med. 2009; 43:22-24. [PubMed: 18927158]

Ericsson KA, Nandagopal K, Roring RW. Toward a science of exceptional achievement: attaining superior performance through deliberate practice. Ann. N. Y. Acad. Sci. 2009; 1172:199-217. [PubMed: 19743555]

Eriksen BA, Eriksen CW. Effects of noise letters upon the identification of a target letter in a nonsearch task. Percept. Psychophys. 1974; 16:143-49.

Espy KA. Using developmental, cognitive, and neuroscience approaches to understand executive control in young children. Dev. Neuropsychol. 2004; 26:379-84. [PubMed: 15276900]

Fairchild G, van Goozen SH, Stollery SJ, Aitken MR, Savage J, et al. Decision making and executive function in male adolescents with early-onset or adolescence-onset conduct disorder and control subjects. Biol. Psychiatry. 2009; 66:162-68. [PubMed: 19362293]

Fan J, Flombaum JI, McCandliss BD, Thomas KM, Posner MI. Cognitive and brain consequences of conflict. Neuroimage. 2002; 18:42-57. [PubMed: 12507442]

Farran, DC.; Wilson, SJ. Is self-regulation malleable? Results from an evaluation of the Tools of the Mind curriculum. Paper presented at Peabody Res. Inst. Colloquium Ser.; Nashville, TN. 2011.

Feng, X.; Bialystok, E.; Diamond, A. Bienn. Meet. Soc. Res. Child Dev. Boston, MA: 2007. Manipulating information in working memory: an advantage for bilinguals.

Ferrer E, Shaywitz BA, Holahan JM, Marchione KE, Shaywitz SE. Uncoupling of reading and IQ over time: empirical evidence for a definition of dyslexia. Psychol. Sci. 2009; 21:93-101. [PubMed: 20424029]

Fiore F, Borella E, Mammarella IC, De Beni R. Age differences in verbal and visuo-spatial working memory updating: evidence from analysis of serial position curves. Memory. 2012; 20:14-27. [PubMed: 22133192]

Flook L, Smalley SL, Kitil JM, Galla BM, Kaiser-Greenland S, et al. Effects of mindful awareness practices on executive functions in elementary school children. J. Appl. School Psychol. 2010; 26:70-95.

Fournet N, Roulin JL, Vallet F, Beaudoin M, Agrigoroaei S, et al. Evaluating short-term and working memory in older adults: French normative data. Aging Ment. Health. 2012; 16:922-30. [PubMed: 22533476]

Frank MJ. Hold your horses: a dynamic computational role for the subthalamic nucleus in decision making. Neural Netw. 2006; 19:1120-36. [PubMed: 16945502]

Friedman NP, Miyake A. The relations among inhibition and interference control functions: a latentvariable analysis. J. Exp. Psychol.: Gen. 2004; 133:101-35. [PubMed: 14979754]

Fry AF, Hale S. Relationships among processing speed, working memory, and fluid intelligence in children. Biol. Psychol. 2000; 54:1-34. [PubMed: 11035218]

Gamboz N, Russo R, Fox E. Age differences and the identity negative priming effect: an updated meta-analysis. Psychol. Aging. 2002; 17:525-31. [PubMed: 12243393]

Garavan H, Kelley D, Rosen A, Rao SM, Stein EA. Practice-related functional activation changes in a working memory task. Microsc. Res. Tech. 2000; 51:54-63. [PubMed: 11002353]

Garon N, Bryson SE, Smith IM. Executive function in preschoolers: a review using an integrative framework. Psychol. Bull. 2008; 134:31-60. [PubMed: 18193994]

Gathercole SE, Pickering SJ, Knight C, Stegmann Z. Working memory skills and educational attainment: evidence from National Curriculum assessments at 7 and 14 years of age. Appl. Cogn. Psychol. 2004; 18:1-16.

Gazzaley A, Cooney JW, McEvoy K, Knight RT, D’Esposito M. Top-down enhancement and suppression of the magnitude and speed of neural activity. J. Cogn. Neurosci. 2005; 17:507-17. [PubMed: 15814009] 
Gazzaley A, Nobre AC. Top-down modulation: bridging selective attention and working memory. Trends Cogn. Sci. 2012; 16:129-35. [PubMed: 22209601]

Gernsbacher MA, Faust ME. The mechanism of suppression: a component of general comprehension skill. J. Exp. Psychol. 1991; 17:245-62.

Georgopoulos AP, Lurito JT, Petrides M, Schwartz AB, Massey JT. Mental rotation of the neuronal population vector. Science. 1989; 243:234-36. [PubMed: 2911737]

Goldsmith HH. Studying temperament via construction of the Toddler Behavior Assessment Questionnaire. Child Dev. 1996; 67:218-35. [PubMed: 8605830]

Gopnik A, Rosati A. Duck or rabbit? Reversing ambiguous figures and understanding ambiguous representations. Dev. Sci. 2001; 4:175-83.

Gupta R, Kar BR, Srinivasan N. Development of task switching and post-error-slowing in children. Behav. Brain Funct. 2009; 5:38. [PubMed: 19754947]

Hale S, Bronik MD, Fry AF. Verbal and spatial working memory in school-age children: developmental differences in susceptibility to interference. Dev. Psychol. 1997; 33:364-71. [PubMed: 9147843]

Hall P, Crossley M, D'Arcy C. Executive function and survival in the context of chronic illness. Ann. Behav. Med. 2010; 39:119-27. [PubMed: 20151234]

Hanania R, Smith LB. Selective attention and attention switching: towards a unified developmental approach. Dev. Sci. 2010; 13:622-35. [PubMed: 20590726]

Hasher L, Stoltzfus ER, Zacks RT, Rypma B. Age and inhibition. J. Exp. Psychol. 1991; 17:163-69.

Hasher, L.; Zacks, RT. Working memory, comprehension, and aging: a review and a new view. In: Bower, GH., editor. The Psychology of Learning and Motivation: Advances in Research and Theory. Academic; San Diego, CA: 1988. p. 193-225.

Heberle, J.; Clune, M.; Kelly, K. Bienn. Meet. Soc. Res. Child Dev. Albuquerque, NM: 1999. Development of young children's understanding of the appearance-reality distinction.

Hedden T, Park D. Aging and interference in verbal working memory. Psychology and Aging. 2001; 16:666-81. [PubMed: 11766920]

Herrigel, E. Zen in the Art of Archery. Vintage; New York: 1999.

Hillman CH, Erickson KI, Kramer AF. Be smart, exercise your heart: exercise effects on brain and cognition. Nat. Rev. Neurosci. 2008; 9:58-65. [PubMed: 18094706]

Hirt ER, Devers EE, McCrea SM. I want to be creative: exploring the role of hedonic contingency theory in the positive mood-cognitive flexibility link. J. Pers. Soc. Psychol. 2008; 94:214-30. [PubMed: 18211173]

Hofmann W, Friese M, Strack F. Impulse and self-control from a dual-systems perspective. Perspect. Psychol. Sci. 2009; 4:162-76.

Holmes J, Gathercole SE, Dunning DL. Adaptive training leads to sustained enhancement of poor working memory in children. Dev. Sci. 2009; 12:F9-15. [PubMed: 19635074]

Hölzel BK, Lazar SW, Gard T, Schuman-Olivier Z, Vago DR, Ott U. How does mindfulness meditation work? Proposing mechanisms of action from a conceptual and neural perspective. Persp. Psychol. Sci. 2011; 6:537-59.

Huang YS, Guilleminault C, Li HY, Yang CM, Wu YY, Chen NH. Attention-deficit/hyperactivity disorder with obstructive sleep apnea: a treatment outcome study. Sleep Med. 2007; 8:18-30. [PubMed: 17157069]

Ikkai A, Curtis CE. Common neural mechanisms supporting spatial working memory, attention and motor intention. Neuropsychologia. 2011; 49:1428-34. [PubMed: 21182852]

Jones LB, Rothbart MK, Posner MI. Development of executive attention in preschool children. Dev. Sci. 2003; 6:498-504.

Kamijo K, Pontifex MB, O’Leary KC, Scudder MR, Wu C-T, et al. The effects of an afterschool physical activity program on working memory in preadolescent children. Dev. Sci. 2011; 14:1046-58. [PubMed: 21884320]

Kane MJ, Brown LH, McVay JC, Silvia PJ, Myin-Germeys I, Kwapil TR. For whom the mind wanders, and when: an experience-sampling study of working memory and executive control in daily life. Psychol. Sci. 2007; 18:614-21. [PubMed: 17614870] 
Kane MJ, Engle RW. Working-memory capacity, proactive interference, and divided attention: limits on long-term memory retrieval. J. Exp. Psychol. 2000; 26:336-58.

Kane MJ, Engle RW. The role of prefrontal cortex in working-memory capacity, executive attention, and general fluid intelligence: an individual-differences perspective. Psychon. Bull. Rev. 2002; 9:637-71. [PubMed: 12613671]

Karayanidis F, Whitson LR, Heathcote A, Michie PT. Variability in proactive and reactive cognitive control processes across the adult lifespan. Front. Psychol. 2011; 2:318. [PubMed: 22073037]

Karbach J, Kray J. How useful is executive control training? Age differences in near and far transfer of task-switching training. Dev. Sci. 2009; 12:978-90. [PubMed: 19840052]

Kendler HH, Kendler TS, Ward JW. An ontogenetic analysis of optional intradimensional and extradimensional shifts. J. Exp. Psychol. 1972; 95:102-9. [PubMed: 5070275]

Kendler TS, Kendler HH. Reversal and nonreversal shifts in kindergarten children. J. Exp. Psychol. 1959; 58:56-60. [PubMed: 13664885]

Kirkham NZ, Cruess L, Diamond A. Helping children apply their knowledge to their behavior on a dimension-switching task. Dev. Sci. 2003; 6:449-67.

Klingberg T. Training and plasticity of working memory. Trends Cogn. Sci. 2010; 14:317-24. [PubMed: 20630350]

Klingberg T, Fernell E, Olesen P, Johnson M, Gustafsson P, et al. Computerized training of working memory in children with ADHD—a randomized, controlled trial. J. Am. Acad. Child Adolesc. Psychiatry. 2005; 44:177-86. [PubMed: 15689731]

Kloo D, Perner J. Disentangling dimensions in the dimensional change card sorting task. Dev. Sci. 2005; 8:44-56. [PubMed: 15647066]

Kochanska G, Coy KC, Murray KT. The development of self-regulation in the first four years of life. Child Dev. 2001; 72:1091-111. [PubMed: 11480936]

Kochanska G, Philibert RA, Barry RA. Interplay of genes and early mother-child relationship in the development of self-regulation from toddler to preschool age. J. Child Psychol. Psychiatry. 2009; 50:1331-38. [PubMed: 19207629]

Kovács AM, Mehler J. Cognitive gains in 7-month-old bilingual infants. Proc. Natl. Acad. Sci. USA. 2009; 106:6556-60. [PubMed: 19365071] This pioneering research demonstrated effects of bilingualism from just listening to two languages without yet speaking.

Kray J. Task-set switching under cue-based versus memory-based switching conditions in younger and older adults. Brain Res. 2006; 1105:83-92. [PubMed: 16387284]

Kray J, Lindenberger U. Adult age differences in task switching. Psychol. Aging. 2000; 15:126-47. [PubMed: 10755295]

Kuo BC, Stokes MG, Nobre AC. Attention modulates maintenance of representations in visual shortterm memory. J. Cogn. Neurosci. 2012; 24:51-60. [PubMed: 21736457]

LaBar KS, Gitelman DR, Parrish TB, Mesulam M. Neuroanatomic overlap of working memory and spatial attention networks: a functional MRI comparison within subjects. Neuroimage. 1999; 10:695-704. [PubMed: 10600415]

Lakes KD, Hoyt WT. Promoting self-regulation through school-based martial arts training. Appl. Dev. Psychol. 2004; 25:283-302.

Landau SM, Garavan H, Schumacher EH, D’Esposito M. Regional specificity and practice: dynamic changes in object and spatial working memory. Brain Res. 2007; 1180:78-89. [PubMed: 17916334]

Lehto JE, Juujärvi P, Kooistra L, Pulkkinen L. Dimensions of executive functioning: evidence from children. Br. J. Dev. Psychol. 2003; 21:59-80.

Lezak, M. Neuropsychological Assessment. Oxford Univ. Press; New York: 1983.

Liew J. Effortful control, executive functions, and education: bringing self-regulatory and socialemotional competencies to the table. Child Dev. Perspect. 2011; 6:105-11.

Lillard A, Else-Quest N. The early years: evaluating Montessori education. Science. 2006; 313:189394. [PubMed: 17008512]

Liston C, McEwen BS, Casey BJ. Psychosocial stress reversibly disrupts prefrontal processing and attentional control. Proc. Natl. Acad. Sci. USA. 2009; 106:912-17. [PubMed: 19139412] 
Louie K, Glimcher PW. Separating value from choice: delay discounting activity in the lateral intraparietal area. J. Neurosci. 2010; 30:5498-507. [PubMed: 20410103]

Lövdén M, Bodammer NC, Kühn S, Kaufmann J, Schütze H, et al. Experience-dependent plasticity of white-matter microstructure extends into old age. Neuropsychologia. 2010; 48:3878-83. [PubMed: 20816877]

$\mathrm{Lu} \mathrm{CH}$, Proctor RW. The influence of irrelevant location information on performance: a review of the Simon and spatial Stroop effects. Psychon. Bull. Rev. 1995; 2:174-207. [PubMed: 24203654]

Luciana M, Conklin HM, Hooper CJ, Yarger RS. The development of nonverbal working memory and executive control processes in adolescents. Child Dev. 2005; 76:697-712. [PubMed: 15892787]

Luciana M, Nelson CA. Assessment of neuropsychological function in children using the Cambridge Neuropsychological Testing Automated Battery (CANTAB): performance in 4- to 12-year-olds. Dev. Neuropsychol. 2002; 22:595-623. [PubMed: 12661972]

Lui M, Tannock R. Working memory and inattentive behaviour in a community sample of children. Behav. Brain Funct. 2007; 3:12. [PubMed: 17319951]

Luna B. Developmental changes in cognitive control through adolescence. Adv. Child Dev. Behav. 2009; 37:233-78. [PubMed: 19673164]

Luna B, Garver KE, Urban TA, Lazar NA, Sweeney JA. Maturation of cognitive processes from late childhood to adulthood. Child Dev. 2004; 75:1357-72. [PubMed: 15369519]

Luna, B.; Merriam, EP.; Minshew, NJ.; Keshavan, MS.; Genovese, CR., et al. Response inhibition improves from late childhood to adulthood: eye movement and fMRI studies. Proc. 6th Annu. Meet. Cogn. Neurosci. Meet.; Washington, DC. 1999.

Lunt L, Bramham J, Morris RG, Bullock PR, Selway RP, et al. Prefrontal cortex dysfunction and "jumping to conclusions": bias or deficit? J. Neuropsychol. 2012; 6:65-78. [PubMed: 22257612]

Mackey AP, Hill SS, Stone SI, Bunge SA. Differential effects of reasoning and speed training in children. Dev. Sci. 2011; 14:582-90. [PubMed: 21477196]

MacLeod CM. Half a century of research on the Stroop effect: an integrative review. Psychol. Bull. 1991; 109:163-203. [PubMed: 2034749]

MacLeod CM, Dodd MD, Sheard ED, Wilson DE, Bibi U. In opposition to inhibition. Psychol. Learn. Motiv. 2003; 43:163-214.

Manjunath NK, Telles S. Improved performance in the Tower of London test following yoga. Indian J. Physiol. Pharmacol. 2001; 45:351-54. [PubMed: 11881575]

Mason M, Norton M, Van Horn JD, Wegner DW, Grafton ST, Macrae CN. Wandering minds: the default network and stimulus-independent thought. Science. 2007; 315:393-95. [PubMed: 17234951]

Mayr U, Liebscher T. Is there an age deficit in the selection of mental sets? Eur. J. Cogn. Psychol. 2001; 13:47-69.

Meiran N. Reconfiguration of processing mode prior to task performance. J. Exp. Psychol.: Learn. Mem. Cogn. 1996; 22:1423-42.

Meiran N, Gotler A. Modeling cognitive control in task switching and aging. Eur. J. Cogn. Psychol. 2001; 13:165-86.

Melby-Lervåg M, Hulme C. Is working memory training effective? A meta-analytic review. Dev. Psychol. 2012 In press.

Milham MP, Banich MT, Claus ED, Cohen NJ. Practice-related effects demonstrate complementary roles of anterior cingulate and prefrontal cortices in attentional control. Neuroimage. 2003; 18:483-93. [PubMed: 12595201]

Miller EK, Cohen JD. An integrative theory of prefrontal cortex function. Annu. Rev. Neurosci. 2001; 24:167-202. [PubMed: 11283309]

Miller HV, Barnes JC, Beaver KM. Self-control and health outcomes in a nationally representative sample. Am. J. Health Behav. 2011; 35:15-27. [PubMed: 20950155]

Miller P, Brody CD, Romo R, Wang XJ. A recurrent network model of somatosensory parametric working memory in the prefrontal cortex. Cereb. Cortex. 2003; 13:1208-18. [PubMed: 14576212] 
Milner, B. Some effects of frontal lobectomy in man. In: Warren, JM.; Akert, K., editors. The Frontal Granular Cortex and Behavior. McGraw-Hill; New York: 1964. p. 313-34.

Mischel W, Ayduk O. Self-regulation in a cognitive-affective personality system: attentional control in the service of the self. Self Identity. 2002; 1:113-20.

Mischel W, Shoda Y, Rodriguez ML. Delay of gratification in children. Science. 1989; 244:933-38. [PubMed: 2658056]

Miyake A, Friedman NP, Emerson MJ, Witzki AH, Howerter A, Wager TD. The unity and diversity of executive functions and their contributions to complex "frontal lobe" tasks: a latent variable analysis. Cogn. Psychol. 2000; 41:49-100. [PubMed: 10945922]

Moffitt, TE. Childhood self-control predicts adult health, wealth, and crime. Multi-Discipl. Symp. Improv. Well-Being Children Youth; Copenhagen. 2012.

Moffitt TE, Arseneault L, Belsky D, Dickson N, Hancox RJ, et al. A gradient of childhood self-control predicts health, wealth, and public safety. Proc. Natl. Acad. Sci. USA. 2011; 108:2693-98. [PubMed: 21262822] Best and longest prospective study of EFs, showing they affect health, wealth, and public safety.

Monsell S. Task switching. Trends Cogn. Sci. 2003; 7:134-40. [PubMed: 12639695]

Monsell S, Driver J. Control of Cognitive Processes: Attention and Performance XVIII. 2000MIT PressCambridge, MA The best single source theory and research task switching (set shifting).

Morrison AB, Chein JM. Does working memory training work? The promise and challenges of enhancing cognition by training working memory. Psychon. Bull. Rev. 2011; 18:46-60. [PubMed: 21327348] Insightful review of EF computerized training that considers methodological problems and what's needed next.

Morrison, FJ.; Ponitz, CC.; McClelland, MM. Self-regulation and academic achievement in the transition to school. In: Calkins, SD.; Bell, M., editors. Child Development at the Intersection of Emotion and Cognition. Am. Psychol. Assoc.; Washington, DC: 2010. p. 203-24.

Mullane JC, Corkum PV, Klein RM, McLaughlin E. Interference control in children with and without ADHD: a systematic review of Flanker and Simon task performance. Child Neuropsychol. 2009; 15:321-42. [PubMed: 18850349]

Munakata Y, Herd SA, Chatham CH, Depue BE, Banich MT, O’Reilly RC. A unified framework for inhibitory control. Trends Cogn. Sci. 2011; 15:453-59. [PubMed: 21889391] Thoughtful articulation of view that there's no need to postulate a separate inhibitory control function.

Munakata Y, Snyder HR, Chatham CH. Developing cognitive control. Curr. Dir. Psychol. Sci. 2012; 21:71-77. [PubMed: 22711982]

Munoz DP, Everling S. Look away: the anti-saccade task and the voluntary control of eye movement. Nat. Rev. Neurosci. 2004; 5:218-28. [PubMed: 14976521]

Munro, S.; Chau, C.; Gazarian, K.; Diamond, A. Dramatically larger flanker effects (6-fold elevation). Poster presented at Cogn. Neurosci. Soc. Annu. Meet.; San Francisco, CA. 2006.

Muraven M. Building self-control strength: practicing self-control leads to improved self-control performance. J. Exp. Soc. Psychol. 2010; 46:465-68. [PubMed: 20401323]

Muraven M, Baumeister RF. Self-regulation and depletion of limited resources: Does self-control resemble a muscle? Psychol. Bull. 2000; 126:247-59. [PubMed: 10748642]

Nelson, JM.; Sheffield, TD.; Chevalier, N.; Clark, CAC.; Espy, KA. Psychobiology of executive function in early development. In: McCardle, P.; Freund, L.; Griffin, JA., editors. Executive Function in Preschool Age Children: Integrating Measurement, Neurodevelopment and Translational Research. Am. Psychol. Assoc.; Washington, DC: 2012. In press

Nieuwenhuis S, Yeung N. Neural mechanisms of attention and control: losing our inhibitions? Nat. Neurosci. 2005; 8:1631-33. [PubMed: 16306886]

Nigg JT. On inhibition/disinhibition in developmental psychopathology: views from cognitive and personality psychology and a working inhibition taxonomy. Psychol. Bull. 2000; 126:220-46. [PubMed: 10748641]

Nigg JT, Butler KM, Huang-Pollock CL, Henderson JM. Inhibitory processes in adults with persistent childhood onset ADHD. J. Consult. Clin. Psychol. 2002; 70:153-57. [PubMed: 11860041] 
Nobre AC, Stokes MG. Attention and short-term memory: crossroads. Neuropsychologia. 2011; 49:1391-92. [PubMed: 21571124] This special issue explores diverse findings on interrelations between selective attention and short-term memory.

Oaten M, Cheng K. Academic examination stress impairs self-control. J. Soc. Clin. Psychol. 2005; 24:254-79.

O’Shaughnessy T, Lane KL, Gresham FM, Beebe-Frankenberger M. Children placed at risk for learning and behavioral difficulties: implementing a school-wide system of early identification and prevention. Remedial Spec. Educ. 2003; 24:27-35.

Owen AM, McMillan KM, Laird AR, Bullmore E. N-back working memory paradigm: a metaanalysis of normative functional neuroimaging studies. Hum. Brain Mapp. 2005; 25:46-59. [PubMed: 15846822]

Owen AM, Morris RG, Sahakian BJ, Polkey CE, Robbins TW. Double dissociations of memory and executive functions in a self-ordered working memory task following frontal lobe excision, temporal lobe excisions or amygdalo-hippocampectomy in man. Brain. 1996; 119:1597-615. [PubMed: 8931583]

Peltsch A, Hemraj A, Garcia A, Munoz DP. Age-related trends in saccade characteristics among the elderly. Neurobiol. Aging. 2011; 32:669-79. [PubMed: 19414208]

Penadés R, Catalán R, Rubia K, Andrés S, Salamero M, Gastó C. Impaired response inhibition in obsessive compulsive disorder. Eur. Psychiatry. 2007; 22:404-10. [PubMed: 17127038]

Perner J, Lang B. What causes 3-year-olds' difficulty on the dimensional change card sorting task? Infant Child Dev. 2002; 11:93-105.

Petrides M. The effect of periarcuate lesions in the monkey on the performance of symmetrically and asymmetrically reinforced visual and auditory go, no-go tasks. J. Neurosci. 1986; 6:2054-63. [PubMed: 3734876]

Petrides M. Impairments on nonspatial self-ordered and externally ordered working memory tasks after lesions of the mid-dorsal part of the lateral frontal cortex in the monkey. J. Neurosci. 1995; 15:359-75. [PubMed: 7823141]

Petrides M, Alivisatos B, Evans AC, Meyer E. Dissociation of human mid-dorsolateral from posterior dorsolateral frontal cortex in memory processing. Proc. Natl. Acad. Sci. USA. 1993; 90:873-77. [PubMed: 8430100]

Petrides M, Milner B. Deficits on subject-ordered tasks after frontal- and temporal-lobe lesions in man. Neuropsychologia. 1982; 20:249-62. [PubMed: 7121793]

Piaget, J. The Child's Conception of Number. Gattegno, C.; Hodgson, FM., translators. Routledge \& Kegan Paul; London: 1952/1941.

Poldrack RA, Sabb FW, Foerde K, Tom SM, Asarnow RF, et al. The neural correlates of motor skill automaticity. J. Neurosci. 2005; 25:5356-64. [PubMed: 15930384]

Posner, MI.; DiGirolamo, GJ. Executive attention: conflict, target detection, and cognitive control. In: Parasuraman, R., editor. The Attentive Brain. MIT Press; Cambridge, MA: 1998. p. 401-23.

Postle BR, Brush LN, Nick AM. Prefrontal cortex and the mediation of proactive interference in working memory. Cogn. Affect. Behav. Neurosci. 2004; 4:600-8. [PubMed: 15849900]

Rachlin H, Ranieri A, Cross D. Subjective probability and delay. J. Exp. Anal. Behav. 1991; 55:23344. [PubMed: 2037827]

Raven J. The Raven's Progressive Matrices: change and stability over culture and time. Cogn. Psychol. 2000; 41:1-48. [PubMed: 10945921]

Raver CC, Jones SM, Li-Grining CP, Metzger M, Champion KM, Sardin L. Improving preschool classroom processes: preliminary findings from a randomized trial implemented in Head Start settings. Early Child. Res. Q. 2008; 23:10-26.

Raver CC, Jones SM, Li-Grining C, Zhai F, Bub K, Pressler E. CSRP's impact on low-income preschoolers' preacademic skills: self-regulation as a mediating mechanism. Child Dev. 2011; 82:362-78. [PubMed: 21291447]

Reason, J.; Mycielska, K. Absent-Minded? The Psychology of Mental Lapses and Everyday Errors. Prentice-Hall; Englewood Cliffs, NJ: 1982.

Richmond LL, Morrison AB, Chein JM, Olson IR. Working memory training and transfer in older adults. Psychol. Aging. 2011; 26:813-22. [PubMed: 21707176] 
Riggs NR, Greenberg MT, Kusché CA, Pentz MA. The mediational role of neurocognition in the behavioral outcomes of a social-emotional prevention program in elementary school students: effects of the PATHS curriculum. Prev. Sci. 2006; 7:91-102. [PubMed: 16572300]

Riggs NR, Spruijt-Metz D, Sakuma KK, Chou CP, Pentz MA. Executive cognitive function and food intake in children. J. Nutr. Educ. Behav. 2010; 42:398-403. [PubMed: 20719568]

Riviere J, Lecuyer R. The C-not-B error: a comparative study. Cogn. Dev. 2003; 18:285-97.

Robbins TW, James M, Owen AM, Sahakian BJ, Lawrence AD, et al. A study of performance on tests from the CANTAB battery sensitive to frontal lobe dysfunction in a large sample of normal volunteers: implications for theories of executive functioning and cognitive aging. J. Int. Neuropsychol. Soc. 1998; 4:474-90. [PubMed: 9745237]

Roberts AC, Robbins TW, Everitt BJ. The effects of intradimensional and extradimensional shifts on visual discrimination learning in humans and non-human primates. Q. J. Exp. Psychol. 1988; 40B:321-41.

Roberts RJ, Pennington BF. An interactive framework for examining prefrontal cognitive processes. Dev. Neuropsychol. 1996; 12:105-26.

Roca M, Parr A, Thompson R, Woolgar A, Torralva T, et al. Executive function and fluid intelligence after frontal lobe lesions. Brain. 2010; 133:234-47. [PubMed: 19903732]

Rogers RD, Monsell S. Costs of a predictable switch between simple cognitive tasks. J. Exp. Psychol.: Gen. 1995; 124:207-31.

Rothbart MK, Ahadi SA, Hershey KL, Fisher P. Investigations of temperament at 3-7 years: the Children's Behavior Questionnaire. Child Dev. 2001; 72:1394-408. [PubMed: 11699677]

Rothbart, MK.; Bates, JE. Temperament. In: Damon, W.; Eisenberg, N., editors. Handbook of Child Psychology. Vol. Vol. 3: Social Emotional and Personality Development. Wiley; New York: 2006. p. 105-76.

Rozas AX, Juncos-Rabadán O, González MS. Processing speed, inhibitory control, and working memory: three important factors to account for age-related cognitive decline. Int. J. Aging Hum. Dev. 2008; 66:115-30. [PubMed: 18453179]

Rueda MR, Posner MI, Rothbart MK. The development of executive attention: contributions to the emergence of self-regulation. Dev. Neuropsychol. 2005; 28:573-94. [PubMed: 16144428]

Rutman AM, Clapp WC, Chadick JZ, Gazzaley A. Early top-down control of visual processing predicts working memory performance. J. Cogn. Neurosci. 2010; 22:1224-34. [PubMed: 19413473]

Sahakian BJ, Morris RG, Evenden JL, Heald A, Levy R, et al. A comparative study of visuospatial memory and learning in Alzheimer-type dementia and Parkinson's disease. Brain. 1988; 111:695-718. [PubMed: 3382917]

Salthouse TA. Influence of processing speed on adult age differences in working memory. Acta Psychol. 1992; 79:155-70.

Sethi A, Mischel W, Aber J, Shoda Y, Rodriguez M. The role of strategic attention deployment in development of self-regulation: predicting preschoolers' delay of gratification from mothertoddler interactions. Dev. Psychol. 2000; 36:767-77. [PubMed: 11081700]

Shipstead Z, Redick TS, Engle RW. Is working memory training effective? Psychol. Bull. 2012; 138:628-54. [PubMed: 22409508] Insightful review of computerized EF training that raises important methodological considerations.

Simpson A, Riggs KJ. Under what conditions do young children have difficulty inhibiting manual actions? Dev. Psychol. 2007; 43:417-28. [PubMed: 17352549]

Simpson A, Riggs KJ, Beck SR, Gorniak SL, Wu Y, et al. Refining the understanding of inhibitory control: how response prepotency is created and overcome. Dev. Sci. 2012; 15:62-73. [PubMed: 22251293]

Smallwood, J.; Schooler, JW. Mind-wandering. In The Oxford Companion to Consciousness. Bayne, T.; Cleermans, A.; Wilken, P., editors. Oxford Univ. Press; Oxford, UK: 2009. p. 443-45.

Smith EE, Jonides J. Storage and executive processes in the frontal lobes. Science. 1999; 283:165761. [PubMed: 10073923] 
Solesio-Jofre E, Lorenzo-López L, Gutiérrez R, Lópezv-Frutos JM, Ruiz-Vargas JM, Maestú F. Agerelated effects in working memory recognition modulated by retroactive interference. J. Gerontol. Ser. A Biol. Sci. 2012; 67:565-72.

Stedron JM, Sahni SD, Munakata Y. Common mechanisms for working memory and attention: the case of perseveration with visible solutions. J. Cogn. Neurosci. 2005; 17:623-31. [PubMed: 15829082]

Stuss DT, Levine B, Alexander MP, Hong J, Palumbo C, et al. Wisconsin Card Sorting Test performance in patients with focal frontal and posterior brain damage: effects of lesion location and test structure on separable cognitive processes. Neuropsychologia. 2000; 38:388-402. [PubMed: 10683390]

Sweeney JA, Rosano C, Berman RA, Luna B. Inhibitory control of attention declines more than working memory during normal aging. Neurobiol. Aging. 2001; 22:39-47. [PubMed: 11164275]

Taylor Tavares JV, Clark L, Cannon DM, Erickson K, Drevets WC, Sahakian BJ. Distinct profiles of neurocognitive function in unmedicated unipolar depression and bipolar II depression. Biol. Psychiatry. 2007; 62:917-24. [PubMed: 17825802]

Theeuwes J. Exogenous and endogenous control of attention: the effect of visual onsets and offsets. Percept. Psychophys. 1991; 49:83-90. [PubMed: 2011456]

Theeuwes J. Top-down and bottom-up control of visual selection. Acta Psychol. 2010; 315:77-99.

Thorell LB, Lindqvist S, Bergman N, Bohlin G, Klingberg T. Training and transfer effects of executive functions in preschool children. Dev. Sci. 2009; 12:106-13. [PubMed: 19120418]

Tun PA, Miller-Martinez D, Lachman ME, Seeman T. Social strain and executive function across the lifespan: the dark (and light) sides of social engagement. Neuropsychol. Dev. Cogn. 2012 In press.

Valle-Inclán F. The locus of interference in the Simon effect: an ERP study. Biol. Psychol. 1996; 43:147-62. [PubMed: 8805969]

Van der Elst W, Hurks P, Wassenberg R, Meijs C, Jolles J. Animal verbal fluency and design fluency in school-aged children: effects of age, sex, and mean level of parental education, and regressionbased normative data. J. Exp. Neuropsychol. 2011; 33:1005-15.

Verbruggen F, Logan GD. Automatic and controlled response inhibition: associative learning in the go/no-go and stop-signal paradigms. J. Exp. Psychol.: Gen. 2008; 137:649-72. [PubMed: 18999358]

Verhaeghen P, Basak C. Ageing and switching of the focus of attention in working memory: results from a modified N-back task. Q. J. Exp. Psychol. 2005; 58:134-54.

von Hecker U, Meiser T. Defocused attention in depressed mood: evidence from source monitoring. Emotion. 2005; 5:456-63. [PubMed: 16366749]

Voss MW, Nagamatsu LS, Liu-Ambrose T, Kramer AF. Exercise, brain, and cognition across the lifespan. J. Appl. Physiol. 2011; 111:1505-13. [PubMed: 21527670]

Wais P, Gazzaley A. The impact of auditory distraction on retrieval of visual memories. Psychon. Bull. Rev. 2011; 18:1090-97. [PubMed: 21938641]

Wais P, Rubens M, Boccanfuso J, Gazzaley A. Neural mechanisms underlying the impact of visual distraction on retrieval of long-term memory. J. Neurosci. 2010; 30:8541-50. [PubMed: 20573901]

Wass S, Porayska-Pomsta K, Johnson MH. Training attentional control in infancy. Curr. Biol. 2011; 21:1-5. [PubMed: 21129968]

Wendelken C, Munakata Y, Baym C, Souza M, Bunge S. Flexible rule use: common neural substrates in children and adults. Dev. Cogn. Neurosci. 2012; 2:329-39. [PubMed: 22669034]

Wiebe SA, Lukowski AF, Bauer PJ. Sequence imitation and reaching measures of executive control: a longitudinal examination in the second year of life. Dev. Neuropsychol. 2010; 35:522-38. [PubMed: 20721773]

Wright A, Diamond A. Dissociating working memory and inhibition: an effect of inhibitory load while keeping working memory load constant. 2012 Manuscript submitted.

Zacks, RT.; Hasher, L. Aging and long-term memory: Deficits are not inevitable. In: Bialystock, E.; Craik, FIM., editors. Lifespan Cognition: Mechanisms of Change. Oxford Univ. Press; New York: 2006. p. 162-77. 
Zanto TP, Gazzaley A. Neural suppression of irrelevant information underlies optimal working memory performance. J. Neurosci. 2009; 29:3059-66. [PubMed: 19279242]

Zanto TP, Hennigan K, Östberg M, Clapp WC, Gazzaley A. Predictive knowledge of stimulus relevance does not influence top-down suppression of irrelevant information in older adults. Cortex. 2010; 46:564-74. [PubMed: 19744649]

Zanto TP, Rubens MT, Thangavel A, Gazzaley A. Causal role of the prefrontal cortex in top-down modulation of visual processing and working memory. Nat. Neurosci. 2011; 14:656-61. [PubMed: 21441920]

Zeidan F, Johnson SK, Diamond BJ, David Z, Goolkasian P. Mindfulness meditation improves cognition: evidence of brief mental training. Conscious. Cogn. 2010; 19:597-605. [PubMed: 20363650]

Zelazo PD, Frye D, Rapus T. An age-related dissociation between knowing rules and using them. Cogn. Dev. 1996; 11:37-63.

Zelazo PD, Mueller U, Frye D, Marcovitch S. The development of executive function in early childhood. Monogr. Soc. Res. Child Dev. 2003; 68:1-137.

Zimprich D, Kurtz T. Individual differences and predictors of forgetting in old age: the role of processing speed and working memory. Neuropsychol. Dev. Cogn. 2012 In press. 


\section{SUMMARY POINTS}

1. EFs and prefrontal cortex are the first to suffer and suffer disproportionately if you are stressed, sad, lonely, or not physically fit. Because EFs are critical for academic achievement, a society that wants its students to excel needs to take seriously that the different parts of the human being are fundamentally interrelated. If emotional, social, or physical needs are ignored, those unmet needs will work against good EFs and hence against academic excellence. A person may be incorrectly diagnosed with an EF disorder when what is really wrong is that stress, sadness, loneliness, lack of sleep, or lack of physical exercise in that person's life are impairing his ability to display the EFs of which he is capable.

2. It's extremely important to help young children have good executive functioning because EFs early in life have been found to predict lifelong achievement, health, wealth, and quality of life.

3. EFs are trainable and can be improved at any age—-probably by many different approaches.

4. Repeated practice is key; exercising and challenging executive functions improves them and thus is beneficial for our mental health, much as physical exercise improves our physical fitness and is beneficial for our bodily health.

5. It is not always beneficial to exert EFs; sometimes thinking about what you are doing and trying to exercise top-down control gets in the way of optimal performance.

6. What is commonly called "fluid intelligence" is the reasoning and problemsolving component of EFs; like other EFs, it can be improved through training and practice.

7. Not all tasks measure what their name implies (e.g., "working memory span" tasks often measure EFs more generally and not just WM). Two widely used measures of response inhibition-the go/no-go and stop-signal tasks-differ from many real-world instances of inhibitory control and appear to be unusual cases of when inhibitory control is needed rather than paradigmatic examples.

8. Although "interference control" (selective attention and cognitive inhibition) is usually grouped under inhibitory control, it may more properly belong with WM. Focusing on information held in working memory might as easily be called keeping your attention focused on those mental contents. Empirically, selective attention and WM could hardly be more tightly linked. Cognitive inhibition is inhibition in the service of protecting WM's mental workspace (keeping irrelevant information out and deleting no-longer-relevant information from WM). It coheres more strongly with working memory measures than with measures of other aspects of inhibition. 


\section{FUTURE ISSUES}

1. What can parents do to aid the development of EFs in their children?

2. For programs and interventions that appear to improve EFs-which are best; what are the best doses, durations, and frequency; how long do benefits last; and does this differ by age, gender, cultural group, or type of program?

3. Given that EF training disproportionately benefits those with poorer EFs and disadvantaged children have poorer EFs, might early EF training reduce social disparities in achievement and health by reducing the EF gap before school entry?

4. Which activities not yet studied might improve EFs? Excellent candidates include the arts (such as theater, orchestra, dance, choir, and filmmaking), caring for an animal, service activities to improve the local or global community, and athletic activities (such as rock climbing, basketball, soccer, capoeira, and rowing crew). Will the type of program end up mattering more, or will the way it is done be more significant?

5. There are so many diverse forms of inhibitory control. What are the commonalities and differences among them? And how do they relate to working memory - can working memory account for all, some, or none of them?

6. Much more in-depth and detailed study is needed of the roles of subcortical regions in EFs.

7. What roles do neurotransmitters other than dopamine and norepinephrine, and interactions among neurotransmitters, play in EFs?

8. Given that sex hormones affect neurotransmitter levels, what sex differences might be found, and how might those impact proper dosages of medications that affect EFs? 


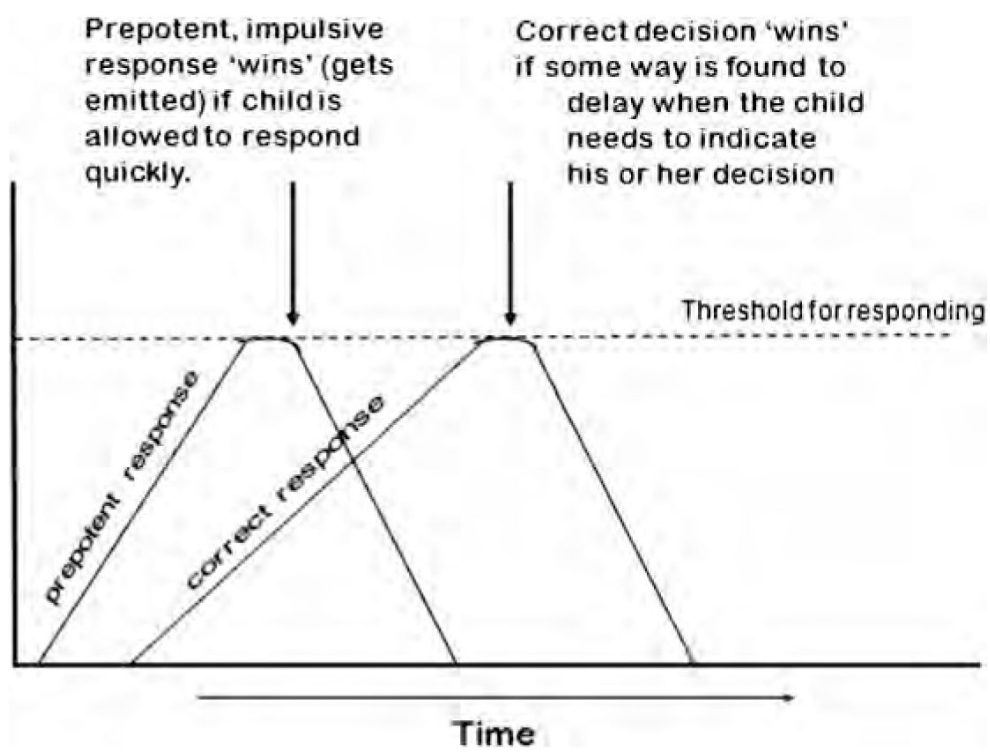

Figure 1.

Passive-dissipation model showing how delay can improve performance on inhibitory tasks (from Simpson et al. 2011). 


\section{Dots Task: Accuracy}

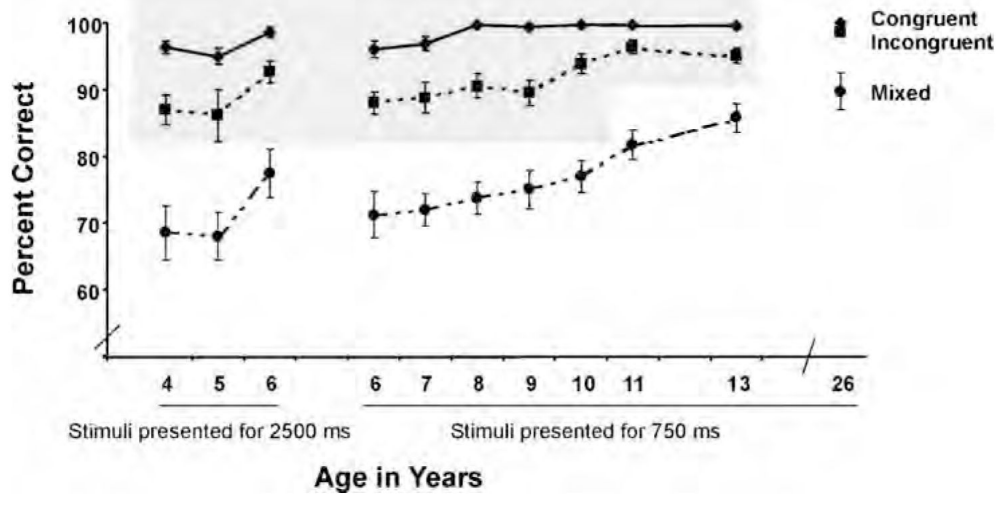

Figure 2.

At every age studied, children were slower and less accurate on the congruent block than on the incongruent block. That effect is completely absent in adults, who are as fast and as accurate on the incongruent block as on the congruent one. The memory demands of those two blocks were the same; they differ only in that the incongruent block requires inhibitory control and the congruent block does not (based on Davidson et al. 2006; this is now called Hearts and Flowers.). 


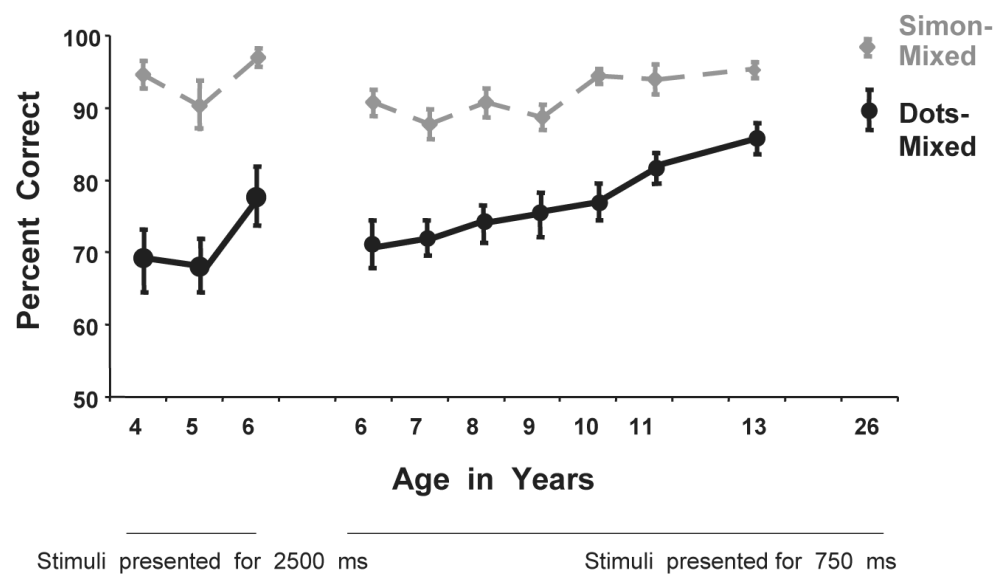

Figure 3.

Comparison of the mixed conditions of the Dots (now called Hearts and Flowers) and Simon tasks in percentage of correct responses (based on Davidson et al. 2006). 


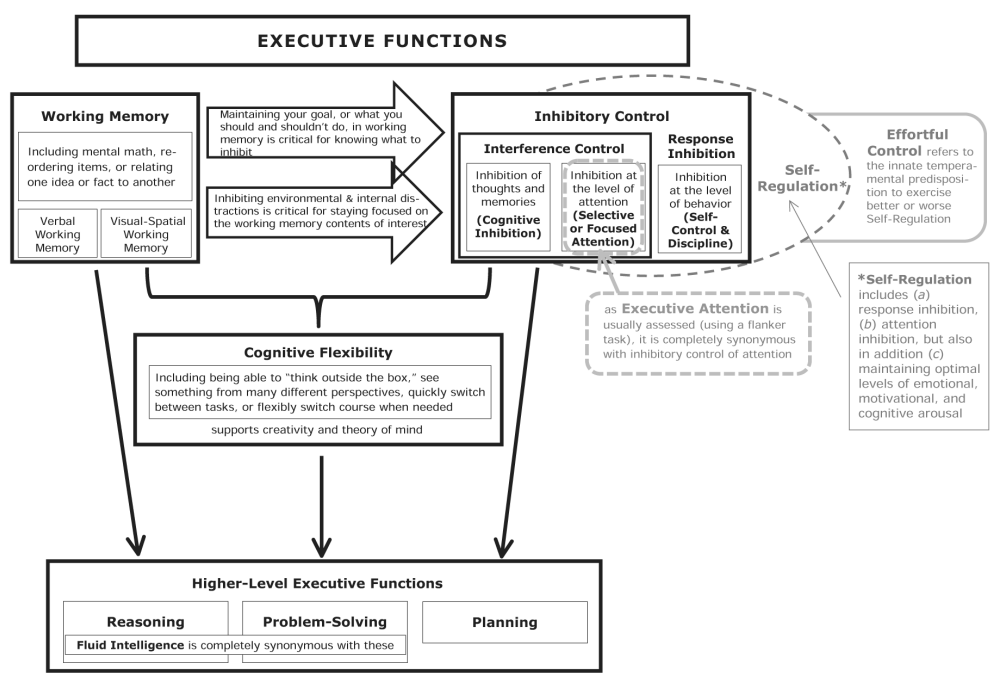

Figure 4.

Executive functions and related terms. 
Table 1

Executive functions (EFs) are important to just about every aspect of life

\begin{tabular}{|c|c|c|}
\hline Aspects of life & The ways in which EFs are relevant to that aspect of life & References \\
\hline \multirow[t]{7}{*}{ Mental health } & EFs are impaired in many mental disorders, including: & \\
\hline & - Addictions & Baler \& Volkow 2006 \\
\hline & - Attention deficit hyperactivity (ADHD) & Diamond 2005, Lui \& Tannock 2007 \\
\hline & - Conduct disorder & Fairchild et al. 2009 \\
\hline & - Depression & Taylor-Tavares et al. 2007 \\
\hline & - Obsessive compulsive disorder (OCD) & Penadés et al. 2007 \\
\hline & - Schizophrenia & Barch 2005 \\
\hline Physical health & $\begin{array}{l}\text { Poorer EFs are associated with obesity, overeating, substance } \\
\text { abuse, and poor treatment adherence }\end{array}$ & $\begin{array}{l}\text { Crescioni et al. 2011, Miller et al. 2011, } \\
\quad \text { Riggs et al. } 2010\end{array}$ \\
\hline Quality of life & People with better EFs enjoy a better quality of life & Brown \& Landgraf 2010, Davis et al. 2010 \\
\hline School readiness & $\begin{array}{l}\text { EFs are more important for school readiness than are IQ or } \\
\text { entry-level reading or math }\end{array}$ & Blair \& Razza 2007, Morrison et al. 2010 \\
\hline School success & $\begin{array}{l}\text { EFs predict both math and reading competence throughout the } \\
\text { school years }\end{array}$ & $\begin{array}{l}\text { Borella et al. 2010, Duncan et al. 2007, } \\
\text { Gathercole et al. } 2004\end{array}$ \\
\hline Job success & $\begin{array}{l}\text { Poor EFs lead to poor productivity and difficulty finding and } \\
\text { keeping a job }\end{array}$ & Bailey 2007 \\
\hline Marital harmony & $\begin{array}{l}\text { A partner with poor EFs can be more difficult to get along with, } \\
\text { less dependable, and/or more likely to act on impulse }\end{array}$ & Eakin et al. 2004 \\
\hline Public safety & $\begin{array}{l}\text { Poor EFs lead to social problems (including crime, reckless } \\
\text { behavior, violence, and emotional outbursts) }\end{array}$ & Broidy et al. 2003, Denson et al. 2011 \\
\hline
\end{tabular}

